\title{
Avaliação dos cursos de graduação da Universidade Federal da Bahia: a biblioteca universitária em foco, de 2010 a $2017^{1}$
}

\author{
Nídia M. L. Lubisco \\ Universidade Federal da Bahia, Instituto de Ciência da Informação, Salvador, BA, Brasil \\ nidialubisco@gmail.com \\ Flávia Bulhões de Sousa \\ flaviabs@ufba.br
}

DOI: https://doi.org/10.26512/rici.v12.n3.2019.17762

Recebido/Recibido/Received: 2018-10-21

Aceitado/Aceptado/Accepted: 2019-04-20

Resumo: Este artigo, resultado parcial de pesquisa, tem como objetivos (1) conhecer a contribuição da biblioteca na avaliação pelo INEP dos cursos de graduação da Universidade Federal da Bahia, tendo como foco as bibliografias básicas e complementares e os periódicos especializados; (2) demonstrar o modus operandi dos avaliadores e seu impacto no resultado da avaliação dos cursos de graduação. Analisaramse as notas atribuídas aos cursos de graduação da UFBA pelos avaliadores, nas visitas in loco, entre os anos de 2010 a 2017. O estudo se configura como uma pesquisa qualitativa e quantitativa, de caráter descritivo, baseada na literatura pertinente e em levantamento documental referente aos instrumentos do INEP e aos relatórios de avaliação dos cursos, elaborados pelos avaliadores. A análise dos dados, comparativamente à realidade conhecida e vivenciada pelas bibliotecas da UFBA, revelou que os critérios de avaliação registrados pelos avaliadores se apresentam muitas vezes subjetivos, não revelando com fidedignidade o estado real das bibliotecas. Conclui-se que ter como únicos indicadores de avaliação da biblioteca universitária as bibliografias básicas e complementares e os periódicos especializados não é uma medida suficiente para configurar se ela cumpre sua função junto à comunidade acadêmica. Ademais, o peso de sua contribuição no cômputo total da avaliação do curso é ínfimo, uma vez que ela integra um elenco de itens da dimensão Infraestrutura. Ante esse cenário, propõe-se que a biblioteca universitária seja transformada numa quarta dimensão a ser avaliada - ao lado da Organização Didáticopedagógica, Corpo Docente e Tutorial e Infraestrutura - na perspectiva que ela tenha representatividade no total da avaliação, por sua função de estrutura fundante da Instituição e para justificar os investimentos feitos.

Palavras-chave: Biblioteca universitária. Avaliação. Ensino de graduação. Universidade Federal da Bahia. Avaliação educacional. INEP.

Evaluation of the undergraduate courses at the Federal University of Bahia: the university library in focus from 2010 to 2017

Abstract: This article, a partial result of research, has as objectives: (1) to know the contribution of libraries in the evaluation by INEP of the undergraduate courses at the Federal University of Bahia, focusing on basic and complementary bibliographies and specialized journals; (2) demonstrate the modus operandi of the evaluators and their impact on the outcome of the evaluation of undergraduate courses. The grades

\footnotetext{
${ }^{1}$ A pesquisa que deu origem a este artigo contou com a participação das graduandas de Biblioteconomia e Documentação da UFBA, Francimar Dias Pereira de Carvalho, Francineide Souza Ferreira, Leidiara lardlei Lopes e Suzane Cipriano Reis, bolsistas do PIBIC.
} 
assigned to UFBA undergraduate courses by the evaluators were analyzed during the on-site visits between 2010 and 2017. The study is configured as a qualitative and quantitative research of descriptive nature, based on the pertinent literature and a document collection regarding the INEP instruments as well as the evaluation reports of the courses, prepared by the evaluators. The data analysis comparatively to the "known-reality" and the reality experienced by UFBA libraries - has revealed that the evaluation criteria registered by the evaluators are often subjective, not revealing with reliability the actual state of the libraries. It is concluded that having both basic bibliography and complementary bibliography and specialized journals as the only evaluation indicators of university libraries is not an enough measure to determine whether it fulfils its function within the academic community. In addition, the weight of its contribution in the total outcome of the evaluation of the courses is insignificant, since it integrates a list of items of the Infrastructure dimension. Given this scenario, it is proposed that the university library be transformed into a fourth dimension to be evaluated - alongside the DidacticPedagogical Organization, Teaching and Tutorial Staff and Infrastructure - in the perspective that it is representative in the total evaluation, due to its function of structure of the Institution as well as to justify the investments made.

Key words: Academic library. Library evaluation. Undergraduate teaching. Federal University of Bahia. Educational evaluation. INEP.

\section{Evaluación de los cursos de graduación de la Universidad Federal de Bahía: la biblioteca universitaria en foco, de 2010 a 2017}

Resumen: Este artículo es el resultado parcial de una investigación y tiene como objetivos (1) conocer la contribución de la biblioteca en los resultados de la evaluación de los estudios de grado de la Universidad Federal de Bahía por el INEP, centrándose en las bibliografías básicas y complementarias, y las revistas especializadas; (2) presentar el modus operandi de los evaluadores y cómo afecta en el resultado de la evaluación de los estudios de grado. Se analizaron las valoraciones atribuidas por los evaluadores en las visitas in loco a los estudios de grado de la UFBA, entre los años 2010 y 2017 . El estudio se configura como una investigación cualitativa y cuantitativa, de carácter descriptivo, fundamentada en la literatura pertinente y en el análisis documental de los instrumentos del INEP y de los informes de evaluación de dichos estudios, elaborados por los evaluadores. El análisis de los datos, comparándolos a la realidad conocida y constatada por las bibliotecas de la UFBA, reveló que los criterios de evaluación registrados por los evaluadores se presentan muchas veces subjetivos, no revelando con idoneidad el estado real de las bibliotecas. Se concluye que tener como únicos indicadores de evaluación de la biblioteca universitaria las bibliografías básicas y complementarias y las revistas especializadas no es una medida suficiente para determinar si cumple su misión con la comunidad académica. Además, es ínfimo el peso de su contribución en el cómputo total de la evaluación, ya que integra un elenco de ítems del apartado Infraestructura. Ante este escenario, se propone que la biblioteca universitaria sea transformada en un cuarto apartado a ser evaluado - al lado de la Organización Didáctico-pedagógica, Cuerpo Docente y Tutorial, e Infraestructura - en la perspectiva que la biblioteca universitaria tenga un peso significativo en el total de la evaluación, por su función de integrar la estructura fundacional de la Institución y para justificar las inversiones realizadas.

Palabras-clave: Biblioteca universitaria. Evaluación. Estudios de grado. Universidad Federal de Bahía. Evaluación educativa. INEP.

\section{Introdução}

A universidade brasileira se consolida como tal a partir da segunda metade do século XX, apesar da existência de cursos de nível superior no Brasil Colônia, mantidos pelos jesuítas, em seus Colégios ${ }^{2}$, e dos esforços de Anísio Teixeira, no primeiro quartel do século XX. No entanto, seu desenvolvimento vem ocorrendo - ainda que dependente de momentos político-

\footnotetext{
${ }^{2}$ Sobre o ensino superior no Brasil Colônia e a formação da universidade brasileira, recomenda-se: CUNHA, L. A. A universidade temporã: o ensino superior da Colônia à era Vargas. 3. ed. São Paulo: Editora UNESP, 2007. 305 p.
} 
governamentais mais ou menos comprometidos com a educação - pela influência de pesquisadores e docentes, cuja iniciativa se concretiza em ações institucionais e atos governamentais, paralelamente a medidas de parlamentares e do próprio Governo, por meio de seus ministérios. Com isto se quer dizer que nem todas as medidas oficiais têm favorecido o desenvolvimento pleno da universidade pública, mas, ainda que de forma sinuosa, ela tem tido uma trajetória ascendente: do total de instituições de ensino superior, cerca de 10\% são públicas e estas são responsáveis por $90 \%$ da pesquisa no país. Dois exemplos recentes têm afetado profundamente essa instituição: do ponto de vista negativo, as medidas do atual governo (2016), já marcado, entre outras perdas, pelos cortes na educação, em geral, e na pesquisa, em particular ${ }^{3}$; do ponto de vista positivo, os dois governos que o antecederam (2003-2016), quando foi implementado o Projeto Reestruturação e Expansão das Universidades (REUNI), dentre outros, como dos mais impactantes no que se refere à ampliação de vagas, abertura de cursos noturnos e concursos para docentes, ademais do impulso dado aos Institutos Federais de Educação, Ciência e Tecnologia (criados pela Lei federal no 11.892, de 29 de dezembro de 2008), atualmente em número de 38, espalhados em 314 campi. (PACHECO, 2009?)

Isto posto e tendo em vista a crença na imprescindibilidade do ensino público, gratuito, de qualidade e inclusivo para o avanço social e justo da sociedade, este artigo abordará as características do instrumental que rege o ensino superior, quanto à sua avaliação, destacando a biblioteca universitária como um dos elementos fundantes da universidade e, apesar disto, o pouco peso com que ela contribui no processo avaliativo dos cursos de graduação.

Justifica-se a inclusão de algumas informações de caráter histórico neste artigo, cujo conteúdo foi necessário para que as bolsistas do PIBIC que participaram da pesquisa se apropriassem de conhecimentos anteriores que fundamentam o percurso das bibliotecas universitárias no Brasil.

\section{Biblioteca universitária e sua relação histórica com o ensino superior}

Desde os primórdios de sua existência, o homem se comunica com seus pares e procura transmitir seu aprendizado a futuras gerações. Inicialmente, o fez de forma oral e, posteriormente, por meio de pinturas rupestres, que registravam suas atividades, até chegar à escrita cuneiforme, por volta do quarto milênio a. C., originado do sistema de contabilidade dos mesopotâmios. Butler (1971) diz que há "A necessidade da sociedade de iniciar, por assim dizer,

\footnotetext{
3 Afirma o presidente da Capes, Abílio Baeta Neves, na reunião anual da SBPC, que "A Coordenação de Aperfeiçoamento de Pessoal de Nível Superior (Capes) já perdeu cerca de R\$ 1 bilhão de orçamento por ano desde 2015 e pode sofrer novo corte em 2018". Disponível em: <http://ciencia.estadao.cJom.br/blogs/herton-escobar/>. Acesso em: 19 jul. 2017.
} 
seus membros mais jovens num estado definido do conhecimento parecem recuar até o passado biológico do homem".

A criação de suportes móveis para a informação, como tabuletas de argila, o papiro e o pergaminho, possibilitou ao homem não só acumular conhecimento, mas reuni-lo no que foram as primeiras bibliotecas da humanidade, sendo a de Nínive - ou de Assurbanipal - considerada a primeira (século 7 a.C.).

De acordo com Cunha (1999), biblioteca é um termo cuja origem está na língua grega bibliotheke, proveniente dos radicais gregos biblio e theke que significam livro e coleção ou depósito, respectivamente - embora ela anteceda em muito o livro, tal como o conhecemos a partir dos códices, sua forma original. Assim, etimologicamente, biblioteca é um depósito de livros, embora, segundo afirma Lemos (2008, p. 101),

\begin{abstract}
Nem toda coleção de livros é uma biblioteca, do mesmo modo que nem toda biblioteca é apenas uma coleção de livros. Para haver uma biblioteca no sentido de instituição social, é preciso que haja três pré-requisitos: a intencionalidade política e social, o acervo e os meios para sua permanente renovação, imperativo de organização e sistematização, uma comunidade de usuários, efetivos ou potenciais, com necessidades de informação conhecidas ou pressupostas, e, por último, mas não menos importante, o local, o espaço físico onde se dará o encontro entre os usuários e os serviços da biblioteca.
\end{abstract}

Independente da tipologia em que se enquadra uma biblioteca - nacional, pública, escolar, universitária e especializada - suas funções gerais tem sido as mesmas, desde sempre: coletar (reunir), organizar, preservar e disseminar informações. Desnecessário dizer que, a depender do momento histórico, a ênfase recai sobre uma ou outra e a depender de sua tipologia essas funções são desdobradas segundo as especificidades pertinentes. (LUBISCO, 2016)

No final da Idade Média, quando surgem as universidades do Ocidente - sendo considerada a de Bolonha, Itália, 1088, a mais antiga da Europa - com elas vêm as bibliotecas universitárias, legado das bibliotecas monacais, e um novo propósito para além da salvaguarda do conhecimento: apoiar o ensino, então representado pelas disciplinas que compunham o trivium (Lógica, Gramática e Retórica) e o quadrivium (Aritmética, Música, Geometria e Astronomia).

Thompson e Carr, em seu livro An introduction to university library administration, datado de 1987, traduzido ao espanhol $(1989$, p. 17), lembravam que, apesar de no Ocidente 4 as bibliotecas universitárias terem suas raízes no século $\mathrm{XI}$, quando nasceram as grandes universidades - Bolonha, Oxford, Paris, Modena, Cambridge, Salamanca, Montepellier, Alcalá de Henares, só para citar algumas - elas constituem um fenômeno de aproximadamente oito

\footnotetext{
${ }^{4}$ As universidades de Fez (Quaraouiyine) e do Cairo (Al-Azhar) foram criadas, respectivamente, em 859 e 988 , respectivamente. Disponível em: https://pt.wikipedia.org/wiki/Lista das universidades mais antigas do mundo
} 
décadas atrás, alinhando-se, segundo a opinião de Arthur T. Hamlin, às viagens aéreas, e assim caracterizando sua contemporaneidade. Tanto é recente sua idade que, na Grã-Bretanha, anos de 1960, sete dos diretores das novas instituições, reunidos em busca de soluções para o tamanho da coleção, não dispunham de nenhum parâmetro para implementá-las. (THOMPSON; CARR, 1989, p. 151)

No caso do Brasil, Cunha e Diógenes (2016), em recente ensaio intitulado A trajetória da biblioteca universitária no Brasil no período de 1901 a 2010, apresentam um panorama histórico, abarcando os séculos XVI a XIX, destacando, na abertura do século XX, a primeira "[...] legislação sobre o funcionamento de bibliotecas ligadas aos Institutos de Ensino Superior, ocasião em que o Presidente Campos Sales aprovou, em 10 de janeiro de 1901, o código dos Institutos Oficiais do Ensino Superior e Secundário.". Por fugir ao escopo deste artigo, o referido ensaio não será comentado, mas fica aqui recomendado como leitura obrigatória aos interessados na relação universidade $\mathrm{x}$ biblioteca universitária, por sua riqueza de dados e informações bibliográficas e históricas.

Lusimar Ferreira, em pesquisa pioneira ${ }^{5}$ no Brasil sobre bibliotecas universitárias, iniciada nos anos de 1970 e publicada em 1980, pelo Instituto Nacional do Livro, já afirmava que "A biblioteca é um dos instrumentos essenciais ao processo de ensino/aprendizagem". Atualmente, não é possível vislumbrar o ensino sem o apoio das bibliotecas que fornecem acesso à informação, auxiliam a pesquisa e proporcionam o desenvolvimento de competências e a formação pessoal e profissional.

Lusimar Ferreira $(1980$, p. 6) declarava que:

[...] a biblioteca é ou deveria ser um dos meios utilizados pelos estabelecimentos de ensino para atingir suas finalidades, ambos devem andar pari passu e, à medida que o ensino vai se renovando, ela deve estar preparada para acompanhá-lo, quando não, ir mesmo à frente, provocando a adoção de novos métodos pedagógicos, a criação de novos hábitos, a formação de novas atitudes em relação aos livros, ao estudo e à pesquisa.

Neste contexto, devem ser destacados, também, dois estudos-marco da área: 1) o de Maria Luiza Monteiro da Cunha (1973, divulgado em 1977), onde ela comenta a mudança de rumo da universidade americana que, em um século, por influência da universidade alemã de Humboldt, passou a priorizar a formação do cientista. Com isso, a consulta às bibliotecas, os

\footnotetext{
${ }^{5}$ Gilda Pires Ferreira, ex-professora da antiga Escola de Biblioteconomia e Documentação, UFBA, em 1977, elaborou um dos documentos também considerados pioneiros sobre bibliotecas universitárias, por encomenda do MEC (FERREIRA, Gilda Pires. A biblioteca universitária em perspectiva sistêmica. Recife: UFPE, 1977. 39 p. Convênio Ministério de Educação e Cultura/DAU).
} 
seminários e os estudos em grupo levam essas unidades de informação a ocupar-se com uma nova realidade, onde:

[...] o professor passou a ser um orientador que incentiva o trabalho individual, promove 'estudos de casos' e faz com que o estudante se aperfeiçoe na investigação bibliográfica segundo seu campo de interesse. (CUNHA, 1977, p. 230-231)

e o 2) de Antonio Miranda (1978), referência nacional para o movimento que deu origem ao Plano Nacional de Bibliotecas Universitárias (PNBU), “[...] marco referencial do pioneirismo em planejamento e ação sistemática para o desenvolvimento das bibliotecas universitárias brasileiras." (LUBISCO, 2001, p. 23). Este Plano nasce oficialmente em 1986 e foi gestado por conta da inconformidade, por parte de bibliotecários, docentes e mesmo de membros do governo, com o fato de a reforma universitária de 1968 não ter incluído a biblioteca no texto da lei. Em seu documento histórico, proferido como palestra no I Seminário Nacional de Bibliotecas Universitárias, Miranda (1978, p. 1) faz uma profunda e ampla análise do setor e “[...] advoga como solução, um plano de estímulo na formação de pessoal bibliotecário e a criação de um Sistema Nacional de Bibliotecas Universitárias."

Com isto se quer destacar que muitos dos problemas da biblioteca universitária brasileira vêm sendo denunciados desde os anos de 1970, embora muitos deles persistam até os dias atuais.

A respeito da conceituação de biblioteca universitária e na perspectiva de difundir esse conhecimento, Lubisco (2014, p. 5) vem defendendo, conceitualmente, que as bibliotecas universitárias,

[...] por sua natureza, desempenham um papel fundante na instituição à qual estão ligadas, por sua função e apoio ao desenvolvimento dos programas de ensino, pesquisa e extensão e inovação. Essa função se consubstancia na sua atuação como recurso didático-pedagógico (laboratório de aprendizagem); como plataforma de conhecimento (considerando-a fonte e local de registro da produção técnica e científica da instituição); e como fator de estímulo à formação e ao desenvolvimento do espírito científico.

Nessa perspectiva, essas unidades de informação devem integrar a Universidade, representando um valor agregado indispensável na sua estrutura e contribuindo diretamente para o cumprimento da missão social da Instituição, por meio do participação no desenvolvimento dos programas de ensino, pesquisa, extensão e inovação. No caso específico do ensino, foco deste artigo, elas devem oferecer conteúdos bibliográficos e informativos que assegurem ao aluno de graduação o atingimento de sua plenitude como estudante, na construção de novos conhecimentos, como cidadão e como futuro profissional.

\section{Ambiente organizacional universitário}


A organização da universidade, pelo que ela comporta em decorrência da sua função acadêmico-social, é complexa, o que exige um esforço, do ponto de vista da sua gestão, para harmonizar as variáveis que a compõem: pessoas, estrutura, tarefas, tecnologia e ambiente (CHIAVENATO, 2003, p. 14).

Ante essa peculiaridade, o planejamento se impõe como uma necessidade imprescindível, tanto do ponto de vista do seu desempenho interno, quanto por sua integração ao sistema nacional da educação superior.

Considerando as quatro funções administrativas a que as organizações estão sujeitas planejamento, organização, direção e controle - “[...] a organização não trabalha na improvisação. Quase tudo nelas é planejado antecipadamente. O planejamento constitui a primeira função administrativa e serve de base para demais". (CHIAVENATO, 2010, p. 51)

Segundo o escopo deste artigo, levaremos em conta apenas o planejamento e o controle, tendo-se o planejamento como primeira etapa da gestão e base dos demais processos, que visa à tomada de decisões orientada aos objetivos e às metas - é o pensar; quanto à formalização do pensar, tem-se o plano, descrição sistematizada das informações que darão a base de sustentação às ações que se quer desenvolver; e o projeto, o detalhamento de uma ação específica dentro da organização. No processo controle é onde se encontram as ações relativas ao acompanhamento e à avaliação das ações, na perspectiva de se averiguar o cumprimento dos objetivos, a necessidade de ajustes ou a correção de rota ou, ainda, quando se confirmam as boas práticas e iniciativas e, assim, se reafirmam as condições de dar continuidade ao que foi prospectado. É quando se obtém os elementos para prestar contas dos investimentos feitos e para demandar novos. É, por assim dizer, quando se sabe do desempenho organizacional.

Segundo Zainko e Pinto:

Administrar uma instituição de ensino superior (IES) não é apenas organizar algo que já existe, que está pronto e acabado; é também produzir novas relações em contextos sociais, políticos, culturais e pedagógicos. (ZAINKO; PINTO, 2008, p. 18):

O planejamento da educação nacional é mencionado na Lei 9.394/96 - Lei de Diretrizes e Bases da Educação Nacional (LDB), onde consta, nos artigos 9 e 12, a responsabilidade da União e a incumbência dos estabelecimentos de ensino no processo de avaliação de rendimento educacional. (BRASIL. Lei 9.394..., 1996). Apesar de não estar explícito, o planejamento da educação do ensino superior encontra-se associado ao conceito de avaliação institucional.

Os instrumentos de planejamento requeridos pela LDB, no âmbito acadêmicoadministrativo da educação superior, são o Plano de Desenvolvimento Institucional (PDI) e o 
Projeto Político-pedagógico do Curso (PPC), sendo o PDI o documento de gestão da Instituição de Ensino Superior, com validade de cinco anos; já o PPC reflete a construção de cada curso de graduação e pós-graduação e é:

[...] um processo intencional, permanente, coletivo e participativo, [...] com base na missão, nos fins e nas diretrizes institucionais e nas especificidades de sua área de conhecimento define os rumos da formação do cidadão/profissional. (ZAINKO; PINTO, 2008, p. 77).

Detalhadamente, os instrumentos de planejamento seguem um fluxo de objetivos e metas dentro da instituição e fornecem preparação da gestão, estrutura, condições de tomada de decisão e a organização do ambiente educacional, cujos resultados serão avaliados pelo governo federal, por diversos indicadores de qualidade para educação superior, os quais se compõem de

Índice Geral de Cursos Avaliados da Instituição (IGC): indicador que avalia a qualidade das instituições de educação superior.

Conceito Preliminar de Curso (CPC): indicador que avalia a qualidade dos cursos superiores.

Indicador de Diferença entre os Desempenhos Observado e Esperado (IDD): indicador de qualidade que busca mensurar o valor agregado pelo curso ao desenvolvimento dos estudantes concluintes, considerando seus desempenhos no Enade e no Enem, como medida proxy (aproximação) das suas características de desenvolvimento ao ingressar no curso de graduação avaliado.

Conceito Enade: indicador de qualidade que avalia o desempenho dos estudantes a partir dos resultados obtidos na aplicação do exame. (INEP6 ${ }^{6}$, $2015^{7}$, grifo nosso)

Tais indicadores e o processo de Avaliação dos Cursos decorrem do resultado do Enade e das avaliações in loco. ${ }^{8}$ Já a Avaliação Institucional ${ }^{9}$ é composta por dois tipos de avaliação: Autoavaliação, realizada pela Comissão Própria de Avaliação - CPA - e a Avaliação Externa da instituição, realizada por comissões designadas pelo INEP.

No que se refere ao interesse deste artigo, destaca-se o processo de Avaliação dos Cursos de Graduação e, dentro dele, segundo Marcos Masetto (2012, p.71 apud GAETA; MASETTO, 2013, p.29), o Projeto Político-pedagógico do Curso, documento que

Consolida o que, o porquê, o quando e como ensinar; Define os perfis dos profissionais que se pretende formar, explicitando seu compromisso social

\footnotetext{
${ }^{6}$ Instituto Nacional de Estudos e Pesquisas Educacionais Anísio Teixeira - INEP, criado pelo Decreto-Lei no 580 , de 30 de julho de 1938 como Instituto Nacional de Estudos Pedagógicos, tendo no Decreto no 71.407, de 20 de novembro de 1972, à mudança institucional e no Decreto no 8.956, de 12 de janeiro de 2017, que altera o Decreto $n$ o 6.317, de 20 de dezembro de 2007, aprova nova estrutura organizacional. Já a Portaria Normativa no 840, de agosto de 2018, dispõe sobre os procedimentos e competências do INEP.

7 INEP. Indicadores de qualidade. Brasília, DF. 2015. Disponível em:

http://portal.inep.gov.br/web/guest/indicadores-de-qualidade. Acesso em: 06 jul. 2018.

8 INEP. Avaliação dos cursos de graduação. Brasília, DF. 2015. Disponível em:

http://portal.inep.gov.br/web/guest/avaliacao-dos-cursos-de-graduacao. Acesso em: 06 jul. 2018.

9 INEP. Avaliação institucional. Brasília, DF. 2015. Disponível em: http://portal.inep.gov.br/web/guest/avaliacaoinstitucional. Acesso em: 06 jul. 2018
} 
com competência e cidadania; Estabelece sua marca, sua missão, sua visão de sociedade e de ensino, ao estabelecer e dar sentido ao compromisso social que determinado curso assume com a formação; planeja as atividades e projetos que o pretende desenvolver nas áreas de ensino, pesquisa e extensão, buscando superar a fragmentação das áreas do conhecimento, integrando as atividades acadêmicas; Organiza a estrutura do curso, com objetivos, componentes curriculares, metodologia e processo avaliativo a serem adotados, assim como os produtos a serem entregues na conclusão do curso; Identifica e aponta perfis para a contratação dos profissionais necessários e capacitados para a realização das atividades acadêmicas; Planeja e institui os recursos necessários para que se alcancem seus objetivos: espaços, laboratórios, bibliotecas, videoteca, internet, secretaria, serviços gerais e toda a infraestrutura necessária para o funcionamento adequado aos fins que se pretende atingir.

O PPC tem a seguinte função, no processo de Autorização de Curso, segundo o art. 43. do Decreto 9.235, de 15 de dezembro de 2017:

II - projeto pedagógico do curso, que informará o número de vagas, os turnos, a carga horária, o programa do curso, as metodologias, as tecnologias e os materiais didáticos, os recursos tecnológicos e os demais elementos acadêmicos pertinentes, incluídas a consonância da infraestrutura física, tecnológica e de pessoal dos polos de educação a distância do curso, quando for o caso;

Pelo exposto, o PPC comporta o Plano de Ensino (PE), instrumento no qual o docente se baseia para atingir o esperado dos alunos em determinada disciplina, considerando o conjunto da matriz curricular. Sua estrutura, constituída de identificação, ementa, objetivos, conteúdo programático, metodologia (técnicas e materiais didáticos e instrucionais), avaliação, bibliografia (básica e complementar) e cronograma, deve nortear, assim, tanto o trabalho docente, como facilitar o desenvolvimento da disciplina por parte dos alunos. Por este motivo, sua elaboração supõe, por parte do docente, levar em conta o contexto, o perfil dos alunos e o Projeto Pedagógico do Curso, conforme indicado anteriormente. (MASETTO, 2015; SPUDEIT, 2014)

Resumindo e reforçando sua função, o Plano de Ensino é um instrumento de comunicação oficial didático-pedagógico, que informa as diferentes instâncias acadêmicas e o alunado sobre o planejamento do período letivo, o qual deve ser elaborado segundo a proposta do PPC e em conformidade com o PDI. Esse é um dos instrumentos através do qual a coordenação do curso pode verificar se está sendo executado tudo o que foi planejado para o desenvolvimento acadêmico do discente.

Dentre os itens do Plano de Ensino, focam-se aqui as bibliografias e os periódicos especializados devido ao impacto na formação do acervo e à relevância na audiência informacional do discente para acompanhar, de um lado, os conteúdos das diferentes disciplinas, de outro, o curso no seu todo. 


\subsection{Bibliografia básica, complementar e os periódicos especializados}

Visando ao processo ensino-aprendizagem, neste caso, no âmbito da educação superior, o material didático e instrucional - aqui restrito às bibliografias - deve alinhar-se ao planejamento institucional, pois, segundo Bruno Ferreira e Cláudio Castro Filho:

Entender a relação existente entre a bibliografia das disciplinas e a universidade, reside em compreender todo o funcionamento do ensino superior, bem como a sua estrutura voltada à formação de conhecimento e a prática científica em sociedade. (FERREIRA; CASTRO FILHO, 2014, p. 23, grifo nosso)

Também há que destacar as diferentes funções da indicação bibliográfica nos Planos de Ensino: referencial teórico oficial adotado pelo docente para a elaboração do conteúdo programático que será ministrado no período letivo; fonte de informação na rotina estudantil, norteadora dos assuntos que serão abordados em sala; informação à biblioteca sobre os títulos das bibliografias básicas e complementares que deverão ser adquiridas e suas respectivas quantidades para estarem disponíveis; meio de o Colegiado de Curso e o Núcleo Docente Estruturante (NDE) verificarem a coerência da bibliografa com o que preconiza o PPC; base para nortear outros professores no planejamento de disciplinas para turmas mais avançadas, considerando a sequência de assuntos dentro matriz curricular.

As indicações bibliográficas devem ser divididas em Bibliografia Básica, Bibliografia Complementar e Periódicos Especializados.

$\mathrm{Na}$ tentativa de orientar adequadamente a definição sobre bibliografia básica e complementar, é preciso que seja realizado uma leitura sobre essas definições, das quais se pode obter entendimento necessário acerca das características de uma e de outra. A esse respeito, há uma sugestão de redação ${ }^{10}$, proposta por Lubisco, para a Bibliografia Básica, como sendo:

É o conjunto de obras (ou fontes) impressas e eletrônicas, cujo conteúdo é essencial e indispensável para o estudo e a pesquisa dos fundamentos teóricos e práticos de determinada área, campo, componente curricular ou disciplina. (LUBISCO, 2014, p. 46)

E Bibliografia Complementar:

É o conjunto de obras (ou fontes) impressas e eletrônicas que ampliam o conteúdo e as abordagens da bibliografia básica, enriquecendo os conhecimentos e práticas contidos/ resultantes das obras fundamentais de determinada área, campo, componente curricular ou disciplina. (LUBISCO, 2014, p. 46)

A escolha das bibliografias básicas e complementares, como dito anteriormente, envolve vários aspectos que não só a disciplina em si. Para a biblioteca é interessante que as indicações circulem amplamente entre os usuários, o que vai demonstrar sua importância

10 Esta proposta objetivou esclarecer as definições dadas pelo INEP (2015, p. 44), consideradas por nós pouco esclarecedoras porquanto se diferenciam entre si apenas pelos adjetivos básica e complementar. 
dentro do conteúdo proposto. Outro ponto a ser observado é se a linguagem utilizada nas publicações selecionadas atende de forma satisfatória o nível de compreensão do discente, segundo o que objetiva cada disciplina. Considera-se que os objetivos expressos no plano de ensino de cada disciplina pressupõem um repertório suficiente para atingi-los. O repertório teórico-prático do discente deve resultar de um processo lógico de construção temática que vai influenciar o resultado final do seu processo de ensino-aprendizagem. Esta é a razão para que o plano de ensino seja elaborado tendo em vista o PPC, pois o conteúdo a ser transmitido em cada disciplina deve estar conectado com os outros do projeto pedagógico para que o repertório do discente cresça de forma coerente e, assim, propicie sua compreensão. Sem um repertório adequado, a bibliografia não tem audiência satisfatória, o que provoca ruído na transmissão do conhecimento (COELHO NETO, 1983, p. 124-125).

Os tipos de fontes de informação utilizadas para a seleção das bibliografias são importantes e é outro aspecto a ser observado pelos docentes e pelos bibliotecários, pois suas características de qualidade têm potencial para refletir-se no nível da produção dos discentes.

O aumento quantitativo de publicações envolve um processo administrativo complexo para as bibliotecas e oneroso para as instituições, tendo-se que a oferta de fontes no mercado editorial aumenta de forma exponencial praticamente na proporção da produção de conhecimento, o que repercute principalmente na necessidade de revisão da atualização das obras indicadas.

O conhecimento de todos esses aspectos, o cumprimento da missão e das funções organizacionais, bem como das normas governamentais resultam na eficiência e eficácia da organização pública. De acordo com Barbosa e Franklin (2011, p. 90):

As organizações públicas têm ainda, pelo menos, mais um fator condicionante que as induzem à busca da eficiência, qual seja o princípio filosófico, ético, moral da probidade que deve permear a sociedade e suas organizações, no sentido de que a verba pública deve ser aplicada com eficácia, sempre na perspectiva da consecução da missão e dos objetivos da organização, de modo a trazer resultados de bem-estar social para todos.

\section{Biblioteca universitária no processo de avaliação das IES no contexto do INEP}

A avaliação é um processo de medição de desempenho organizacional, por meio da verificação do cumprimento dos objetivos traçados no planejamento. Ainda que seja feita $a$ priori, a posteriori ou concomitantemente à ação, muda a modalidade, mas não sua função de corrigir rumos, confirmar acertos, ampliar possibilidades, justificar investimentos e demandar novos, além de prestar contas dos gastos. Com se trata de um processo de exposição, ainda não comum encontrar-se resistência para sua concretização, o que exige um trabalho preliminar de sensibilização e envolvimento da comunidade - no caso da Universidade - visando ao 
desenvolvimento de uma cultura orientada aos benefícios que uma avaliação participativa e honesta pode trazer à Instituição. Como insumo básico do planejamento, quanto mais ampla e precisa ela for, mais reais e úteis serão seus resultados. Por ser complexa e laboriosa, a literatura recomenda que seja feita atentando-se para dois aspectos fundamentais: a mesma periodicidade e de forma sistematizada, pois só assim serão obtidas séries históricas que possibilitarão análises mais profundas de determinada situação, fenômeno ou organização, bem como a construção de padrões e indicadores de desempenho.

Todo o processo de avaliação do sistema de ensino superior nacional está referendado pela Lei 9.394/96 - Lei de Diretrizes e Bases da Educação Nacional - LDB, no seu art. 9, no inciso VI e IX, que incumbe a União de:

[...] VI - assegurar processo nacional de avaliação do rendimento escolar no ensino fundamental, médio e superior, em colaboração com os sistemas de ensino, objetivando a definição de prioridades e a melhoria da qualidade do ensino;

[...] IX - autorizar, reconhecer, credenciar, supervisionar e avaliar, respectivamente, os cursos das instituições de educação superior e os estabelecimentos do seu sistema de ensino. (BRASIL, Lei no 9.394..., 1996. p. 3)

Para assegurar a qualidade desse sistema, o Estado, dispõe de três funções: regulação, supervisão e avaliação, regulamentadas pelo Decreto no 9.235, de 15 de dez. 2017 (art. 1ㅇ):

[...] Este Decreto dispõe sobre o exercício das funções de regulação, supervisão e avaliação das instituições de educação superior - IES e dos cursos superiores de graduação e de pós-graduação lato sensu, nas modalidades presencial e a distância, no sistema federal de ensino. (BRASIL. Lei no 9.235..., 2017. p. 1)

Para instituir quem exercerá tais funções, o art. 3ำ do referido Decreto determina:

[...] As competências para as funções de regulação, supervisão e avaliação no sistema federal de ensino serão exercidas pelo Ministério da Educação, pelo Conselho Nacional de Educação - CNE, pelo Instituto Nacional de Estudos e Pesquisas Educacionais Anísio Teixeira - Inep e pela Comissão Nacional de Avaliação da Educação Superior - Conaes, conforme estabelecido neste Decreto. (BRASIL. Lei no 9.235..., 2017. p. 2)

A avaliação governamental da educação superior ganhou destaque a partir de 1993, com o Programa de Avaliação Institucional das Universidades Brasileiras (PAIUB) e hoje é realizada mediante os Atos de Permanência ${ }^{11}$ no Sistema Federal de Ensino, pelo Sistema Nacional de Avaliação da Educação Superior (SINAES), instituído pela Lei 10.861, de 14 de abril de 2004 , tendo como objetivo, segundo seu artigo 3으,

[...] identificar o seu perfil e o significado de sua atuação, por meio de suas atividades, cursos, programas, projetos e setores, considerando as diferentes dimensões institucionais [...] (BRASIL, Lei n. 10.861..., 2004. p. 1).

11 Atos de permanência (Recredenciamento e Transformação de Organização Acadêmica; Reconhecimento e Renovação de Reconhecimento). (INEP, 2017, p. 1) 
Todo o processo avaliativo do Sinaes é integrado por vários instrumentos que se complementam entre si, que permitem a atribuição de alguns conceitos e a sua ordenação, numa escala de cinco níveis para cada uma das dimensões avaliadas. Esse conjunto de instrumentos avaliativos serve, de certa forma, para corrigir o rumo de planejamento que a Instituição está tomando em suas ações, pois a União respeita a autonomia administrativa universitária. Contudo, esse processo avaliativo afeta, de forma complexa, o ambiente universitário, onde todos os atores são avaliados, pois, de acordo com Sinaes, a avalição tem “[...] por finalidade a melhoria da qualidade da educação superior." (BRASIL. Lei no10.861..., 2004. p. 1)

Sublinha-se que além dos indicadores de qualidade do Sistema da Educação Superior, no caso da avaliação institucional e da avaliação dos cursos de graduação desenvolvidas pelo INEP, estabelecidos nos Instrumentos pertinentes, é apropriado não excluir o desenvolvimento de outros sistemas, muitas vezes setoriais, que podem vir a enriquecer ou mesmo ampliar o escopo da avaliação governamental, mas que se destinam, com mais especificidade, para a autoavaliação setorial ou da instituição como um todo.

A avaliação institucional integra duas modalidades:

Autoavaliação - Coordenada pela Comissão Própria de Avaliação (CPA) de cada instituição e orientada pelas diretrizes e pelo roteiro da autoavaliação institucional da CONAES.

Avaliação Externa - Realizada por comissões designadas pelo INEP, a avaliação externa tem como referência os padrões de qualidade para a educação superior expressos nos instrumentos de avaliação e os relatórios das autoavaliações. O processo de avaliação externa independente de sua abordagem e se orienta por uma visão multidimensional que busque integrar sua natureza formativa e de regulação numa perspectiva de globalidade. Em seu conjunto, os processos avaliativos devem constituir um sistema que permita a integração das diversas dimensões da realidade avaliada, assegurando as coerências conceitual, epistemológica e prática, bem como o alcance dos objetivos dos diversos instrumentos e modalidades. (INEP, $\left.2015^{12}\right)$

É por meio das avaliações que se pode verificar se o planejamento elaborado pela universidade e fixado no seu Plano de Desenvolvimento Institucional (PDI) e nos Projetos Pedagógicos dos Cursos (PPC) vem sendo cumprido e quais as suas falhas e êxitos.

A Avalição dos Cursos de Graduação se alicerça em três atos autorizativos, que passam a vigorar após o credenciamento institucional e está regulamentada pelo Decreto no 9.235, de 15 de dezembro de 2017, com as seguintes finalidades:

Para autorização: Essa avaliação é feita quando uma instituição pede autorização ao MEC para abrir um curso. Ela é feita por dois avaliadores, sorteados entre os cadastrados no Banco Nacional de Avaliadores (BASis). Os avaliadores seguem parâmetros de um documento próprio que orienta as visitas, os instrumentos para avaliação in loco. São avaliadas as três dimensões do curso quanto à adequação ao projeto proposto: a organização

\footnotetext{
12 Disponível em: http://portal.inep.gov.br/web/guest/avaliacao-institucional.
} 
didático-pedagógica; o corpo docente e técnico-administrativo e as instalações físicas.

Para reconhecimento: Quando a primeira turma do curso novo entra na segunda metade do curso, a instituição deve solicitar seu reconhecimento. É feita, então, uma segunda avaliação para verificar se foi cumprido o projeto apresentado para autorização. Essa avaliação também é feita segundo instrumento próprio, por comissão de dois avaliadores do BASis, por dois dias. São avaliados a organização didático-pedagógica, o corpo docente, discente, técnico-administrativo e as instalações físicas.

Para renovação de reconhecimento: Essa avaliação é feita de acordo com o Ciclo do Sinaes, ou seja, a cada três anos. É calculado o Conceito Preliminar do Curso (CPC) e aqueles cursos que tiverem conceito preliminar 1 ou 2 serão avaliados in loco por dois avaliadores ao longo de dois dias. Os cursos que não fazem Enade, obrigatoriamente terão visita in loco para este ato autorizado. (INEP, 2015 ${ }^{13}$ )

A partir de outubro de 2017, o INEP, a Diretoria de Avaliação da Educação Superior (Daes) e a Coordenação-Geral de Avaliação dos Cursos de Graduação e Instituições de Ensino Superior (CGACGIES), com suas prerrogativas de conceber, planejar, coordenar e operacionalizar a avaliação, realizaram alterações substanciais nos instrumentos de avaliação in loco de acordo com a "natureza do ato autorizativo: atos de entrada (credenciamento; autorização) e atos de permanência (recredenciamento e transformação de organização acadêmica; reconhecimento e renovação de reconhecimento)". (INEP. Nota técnica, 2017, p. 1).

As instituições particulares que querem entrar no Sistema Federal de Ensino precisam solicitar seu credenciamento; posteriormente, visando sua permanência ou transformação da organização acadêmica de faculdade em universidade ou centro universitário, precisam fazer o recredenciamento institucional. As IES particulares também precisam de autorização, reconhecimento e renovação do Ministério da Educação para manter os cursos de graduação em funcionamento.

Já para instituições federais de ensino superior (IFES), o Decreto no 9.235, de 15 de dezembro 2017, estabelece no seu art. 41, parágrafo 6, que para a autorização de funcionamento de um curso de graduação: “O Ministério da Educação poderá instituir processo simplificado para autorização de cursos e aumento de vagas para as IFES, nos cursos referidos no caput." e para reconhecimento e renovação de reconhecimento, o art. 45, parágrafo 4, estabelece: "O Ministério da Educação poderá instituir processo simplificado para reconhecimento e renovação de reconhecimento de cursos das IFES."

Nos novos instrumentos de Avaliação dos Cursos de Graduação - presencial e a distância (2017), foram separados os Atos Autorizativos ${ }^{14}$ dos Atos Regulatórios ${ }^{15}$, estando as alterações na redação dos indicadores referentes às dimensões avaliadas sinalizadas nos Quadros 1 a 3 abaixo.

\footnotetext{
$13<$ http://portal.inep.gov.br/web/guest/avaliacao-dos-cursos-de-graduacao>.

${ }^{14}$ Atos autorizativos: Credenciamento (Institucional) e Autorização (Cursos de Graduação).

${ }^{15}$ Atos Regulatórios: Recredenciamento, Transformação de Organização Acadêmica (Institucional) e Reconhecimento, Renovação de Reconhecimento.
} 
Quadro 1 - Indicadores da Dimensão 1 (Organização Didático-Pedagógica) nos Atos Autorizativo e Regulatório

\begin{tabular}{|c|c|c|c|c|}
\hline \multicolumn{5}{|c|}{ Instrumento de Avaliação dos Cursos de Graduação (INEP, out. 2017) } \\
\hline \multirow{2}{*}{ 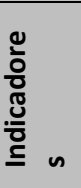 } & Autorização & $\approx$ & $\begin{array}{c}\text { Reconhecimento e Renovação de } \\
\text { Reconhecimento }\end{array}$ & 巳 0 \\
\hline & $\begin{array}{c}\text { Dimensão } 1 \\
\text { (Organização Didático-Pedagógica) }\end{array}$ & 40 & $\begin{array}{c}\text { Dimensão } 1 \\
\text { (Organização Didático-Pedagógica) }\end{array}$ & 30 \\
\hline 1.1 & Políticas institucionais no âmbito do curso & & Políticas institucionais no âmbito do curso & \\
\hline 1.2 & Objetivos do curso & & Objetivos do curso & \\
\hline 1.3 & Perfil profissional do egresso & & Perfil profissional do egresso & \\
\hline 1.4 & Estrutura curricular & & Estrutura curricular & \\
\hline 1.5 & Conteúdos curriculares & & Conteúdos curriculares & \\
\hline 1.6 & Metodologia & & Metodologia & \\
\hline 1.7 & Estágio curricular supervisionado & & Estágio curricular supervisionado & \\
\hline 1.8 & $\begin{array}{l}\text { Estágio curricular supervisionado - relação } \\
\text { com a rede de escolas da Educação Básica }\end{array}$ & & $\begin{array}{l}\text { Estágio curricular supervisionado - relação } \\
\text { com a rede de escolas da educação básica }\end{array}$ & \\
\hline 1.9 & $\begin{array}{l}\text { Estágio curricular supervisionado - relação } \\
\text { teoria e prática }\end{array}$ & & $\begin{array}{l}\text { Estágio curricular supervisionado - relação } \\
\text { teoria e prática }\end{array}$ & \\
\hline 1.10 & Atividades complementares & & Atividades complementares & \\
\hline 1.11 & Trabalho de Conclusão de Curso (TCC) & & Trabalhos de Conclusão de Curso (TCC) & \\
\hline 1.12 & Apoio ao discente & & Apoio ao discente & \\
\hline 1.13 & $\begin{array}{l}\text { Gestão do curso e os processos de } \\
\text { avaliação interna e externa }\end{array}$ & & $\begin{array}{l}\text { Gestão do curso e os processos de } \\
\text { avaliação interna e externa }\end{array}$ & \\
\hline 1.14 & Atividades de tutoria & & Atividades de tutoria & \\
\hline 1.15 & $\begin{array}{l}\text { Conhecimentos, habilidades e atitudes } \\
\text { necessárias às atividades de tutoria }\end{array}$ & & $\begin{array}{l}\text { Conhecimentos, habilidades e atitudes } \\
\text { necessárias às atividades de tutoria }\end{array}$ & \\
\hline 1.16 & $\begin{array}{l}\text { Tecnologias de Informação e Comunicação } \\
\text { (TIC) no processo ensino-aprendizagem }\end{array}$ & & $\begin{array}{l}\text { Tecnologias de Informação e Comunicação } \\
\text { (TIC) no processo ensino-aprendizagem }\end{array}$ & \\
\hline 1.17 & Ambiente Virtual de Aprendizagem (AVA) & & Ambiente Virtual de Aprendizagem (AVA) & \\
\hline 1.18 & Material didático & & Material didático & \\
\hline 1.19 & $\begin{array}{l}\text { Procedimentos de acompanhamento e de } \\
\text { avaliação dos processos de ensino- } \\
\text { aprendizagem }\end{array}$ & & $\begin{array}{l}\text { Procedimentos de acompanhamento e de } \\
\text { avaliação dos processos de ensino- } \\
\text { aprendizagem }\end{array}$ & \\
\hline 1.20 & Número de vagas & & Número de vagas & \\
\hline 1.21 & $\begin{array}{l}\text { Integração com as redes públicas de } \\
\text { ensino }\end{array}$ & & $\begin{array}{l}\text { Integração com as redes públicas de } \\
\text { ensino }\end{array}$ & \\
\hline 1.22 & $\begin{array}{l}\text { Integração do curso com o sistema local e } \\
\text { regional de saúde (SUS) }\end{array}$ & & $\begin{array}{l}\text { Integração do curso com o sistema local e } \\
\text { regional de saúde (SUS) }\end{array}$ & \\
\hline 1.23 & $\begin{array}{l}\text { Atividades práticas de ensino para áreas da } \\
\text { saúde }\end{array}$ & & $\begin{array}{l}\text { Atividades práticas de ensino para áreas da } \\
\text { saúde }\end{array}$ & \\
\hline 1.24 & $\begin{array}{l}\text { Atividades práticas de ensino para } \\
\text { licenciaturas }\end{array}$ & & $\begin{array}{l}\text { Atividades práticas de ensino para } \\
\text { licenciaturas }\end{array}$ & \\
\hline
\end{tabular}

Fonte: Dados da pesquisa. 
Quadro 2 - Indicadores da Dimensão 2 (Corpo Docente e Tutorial) nos Atos Autorizativo e Regulatório

\begin{tabular}{|c|c|c|c|}
\hline \multirow{2}{*}{ 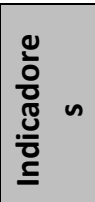 } & Autorização & $\cong \$$ & $\begin{array}{l}\text { Reconhecimento e Renovação de } \\
\text { Reconhecimento }\end{array}$ \\
\hline & $\begin{array}{c}\text { Dimensão } 2 \\
\text { (Corpo Docente e Tutorial) }\end{array}$ & 20 & $\begin{array}{c}\text { Dimensão } 2 \\
\text { (Corpo Docente e Tutorial) }\end{array}$ \\
\hline 2.1 & Núcleo Docente Estruturante - NDE & & Núcleo Docente Estruturante - NDE \\
\hline 2.2 & Equipe multidisciplinar & & Equipe multidisciplinar \\
\hline 2.3 & $\begin{array}{l}\text { Regime de trabalho do coordenador de } \\
\text { curso }\end{array}$ & & Atuação do coordenador \\
\hline 2.4 & Corpo docente: titulação & & $\begin{array}{l}\text { Regime de trabalho do coordenador de } \\
\text { curso }\end{array}$ \\
\hline 2.5 & $\begin{array}{l}\text { Regime de trabalho do corpo docente do } \\
\text { curso }\end{array}$ & & Corpo docente: titulação \\
\hline 2.6 & $\begin{array}{l}\text { Experiência profissional do docente } \\
\text { (excluída a experiência no exercício da } \\
\text { docência superior) }\end{array}$ & & $\begin{array}{l}\text { Regime de trabalho do corpo docente do } \\
\text { curso }\end{array}$ \\
\hline 2.7 & $\begin{array}{l}\text { Experiência no exercício da docência na } \\
\text { educação básica }\end{array}$ & & Experiência profissional do docente \\
\hline 2.8 & $\begin{array}{l}\text { Experiência no exercício da docência } \\
\text { superior }\end{array}$ & & $\begin{array}{l}\text { Experiência no exercício da docência na } \\
\text { educação básica }\end{array}$ \\
\hline 2.9 & $\begin{array}{l}\text { Experiência no exercício da docência na } \\
\text { educação a distância }\end{array}$ & & $\begin{array}{l}\text { Experiência no exercício da docência } \\
\text { superior }\end{array}$ \\
\hline 2.10 & $\begin{array}{l}\text { Experiência no exercício da tutoria na } \\
\text { educação a distância }\end{array}$ & & $\begin{array}{l}\text { Experiência no exercício da docência na } \\
\text { educação a distância }\end{array}$ \\
\hline 2.11 & $\begin{array}{l}\text { Atuação do colegiado de curso ou } \\
\text { equivalente }\end{array}$ & & $\begin{array}{l}\text { Experiência no exercício da tutoria na } \\
\text { educação a distância }\end{array}$ \\
\hline 2.12 & $\begin{array}{l}\text { Titulação e formação do corpo de tutores } \\
\text { do curso }\end{array}$ & & $\begin{array}{l}\text { Atuação do colegiado de curso ou } \\
\text { equivalente }\end{array}$ \\
\hline 2.13 & $\begin{array}{l}\text { Experiência do corpo de tutores em } \\
\text { educação a distância }\end{array}$ & & $\begin{array}{l}\text { Titulação e formação do corpo de tutores } \\
\text { do curso }\end{array}$ \\
\hline 2.14 & $\begin{array}{l}\text { Interação entre tutores (presenciais - } \\
\text { quando for o caso - e a distância), } \\
\text { docentes e coordenadores de curso a } \\
\text { distância }\end{array}$ & & $\begin{array}{l}\text { Experiência do corpo de tutores em } \\
\text { educação a distância }\end{array}$ \\
\hline 2.15 & $\begin{array}{l}\text { Produção científica, cultural, artística ou } \\
\text { tecnológica }\end{array}$ & & $\begin{array}{l}\text { Interação entre tutores (presenciais - } \\
\text { quando for o caso - e a distância), } \\
\text { docentes e coordenadores de curso a } \\
\text { distância }\end{array}$ \\
\hline 2.16 & & & $\begin{array}{l}\text { Produção científica, cultural, artística ou } \\
\text { tecnológica }\end{array}$ \\
\hline
\end{tabular}

Fonte: Dados da pesquisa.

Legenda: Os quadros preenchidos na cor vermelha não contêm Indicadores comparativos com os atos autorizativos. Os quadros na cor amarela são Indicadores que coincidem 
Quadro 3 - Indicadores da Dimensão 3 (Infraestrutura) nos Atos Autorizativo e Regulatório

\begin{tabular}{|c|c|c|c|c|}
\hline$\frac{y}{0}$ & Autorização & $\check{\beth}$ & $\begin{array}{l}\text { Reconhecimento e Renovação de } \\
\text { Reconhecimento }\end{array}$ & $\check{\beth}$ \\
\hline$\stackrel{\frac{.0}{\sigma}}{\underline{\underline{\sigma}}}$ & $\begin{array}{c}\text { Dimensão } 3 \\
\text { (Infraestrutura) }\end{array}$ & 40 & $\begin{array}{c}\text { Dimensão } 3 \\
\text { (Infraestrutura) }\end{array}$ & 30 \\
\hline 3.1 & $\begin{array}{l}\text { Espaço de trabalho para docentes em } \\
\text { Tempo Integral }\end{array}$ & & $\begin{array}{l}\text { Espaço de trabalho para docentes em } \\
\text { tempo integral }\end{array}$ & \\
\hline 3.2 & Espaço de trabalho para o coordenador & & Espaço de trabalho para o coordenador & \\
\hline 3.3 & Sala coletiva de professores & & Sala coletiva de professores & \\
\hline 3.4 & Salas de aula & & Salas de aula & \\
\hline 3.5 & $\begin{array}{l}\text { Acesso dos alunos a equipamentos de } \\
\text { informática }\end{array}$ & & $\begin{array}{l}\text { Acesso dos alunos a equipamentos de } \\
\text { informática }\end{array}$ & \\
\hline 3.6 & $\begin{array}{l}\text { Bibliografia básica por Unidade } \\
\text { Curricular (UC) }\end{array}$ & & $\begin{array}{l}\text { Bibliografia básica por Unidade } \\
\text { Curricular (UC) }\end{array}$ & \\
\hline 3.7 & $\begin{array}{l}\text { Bibliografia complementar por Unidade } \\
\text { Curricular (UC) }\end{array}$ & & $\begin{array}{l}\text { Bibliografia complementar por Unidade } \\
\text { Curricular (UC) }\end{array}$ & \\
\hline 3.8 & $\begin{array}{l}\text { Laboratórios didáticos de formação } \\
\text { básica }\end{array}$ & & $\begin{array}{l}\text { Laboratórios didáticos de formação } \\
\text { básica }\end{array}$ & \\
\hline 3.9 & $\begin{array}{l}\text { Laboratórios didáticos de formação } \\
\text { específica }\end{array}$ & & $\begin{array}{l}\text { Laboratórios didáticos de formação } \\
\text { específica }\end{array}$ & \\
\hline 3.10 & $\begin{array}{l}\text { Laboratórios de ensino para a área de } \\
\text { saúde }\end{array}$ & & $\begin{array}{l}\text { Laboratórios de ensino para a área de } \\
\text { saúde }\end{array}$ & \\
\hline 3.11 & Laboratórios de habilidades & & Laboratórios de habilidades & \\
\hline 3.12 & $\begin{array}{l}\text { Unidades hospitalares e complexo } \\
\text { assistencial conveniado }\end{array}$ & & $\begin{array}{l}\text { Unidades hospitalares e complexo } \\
\text { assistencial conveniado }\end{array}$ & \\
\hline 3.13 & Biotérios & & Biotérios & \\
\hline 3.14 & $\begin{array}{l}\text { Processo de controle de produção ou } \\
\text { distribuição de material didático } \\
\text { (logística) }\end{array}$ & & $\begin{array}{l}\text { Processo de controle de produção ou } \\
\text { distribuição de material didático } \\
\text { (logística) }\end{array}$ & \\
\hline 3.15 & $\begin{array}{l}\text { Núcleo de práticas jurídicas: atividades } \\
\text { básicas e arbitragem, negociação, } \\
\text { conciliação, mediação e atividades } \\
\text { jurídicas reais }\end{array}$ & & $\begin{array}{l}\text { Núcleo de práticas jurídicas: atividades } \\
\text { básicas e arbitragem, negociação, } \\
\text { conciliação, mediação e atividades } \\
\text { jurídicas reais }\end{array}$ & \\
\hline 3.16 & $\begin{array}{l}\text { Ambientes profissionais vinculados ao } \\
\text { curso }\end{array}$ & & Comitê de Ética em Pesquisa (CEP) & \\
\hline 3.17 & & & $\begin{array}{l}\text { Comitê de Ética na Utilização de Animais } \\
\text { (CEUA) }\end{array}$ & \\
\hline 3.18 & & & $\begin{array}{l}\text { Ambientes profissionais vinculados ao } \\
\text { curso }\end{array}$ & \\
\hline
\end{tabular}

Fonte: Dados da pesquisa.

Legenda: Os quadros preenchidos na cor vermelha não contêm Indicadores comparativos.

Os quadros preenchidos na cor verde são Indicadores novos comparativamente aos atos autorizativos.

Os quadros preenchidos na cor azul são os Indicadores de avaliação dos elementos que representam a biblioteca.

Em todos os casos, as dimensões a serem avaliadas são a Organização Didáticopedagógica (ODP), o Corpo Docente e Tutorial (CDT) e a Infraestrutura (INF), com seus 
respectivos indicadores; dentre eles, há apenas dois elementos representativos da biblioteca, quais sejam, a Bibliografia Básica (BB) e a Bibliografia Complementar (BC), sendo que o indicador Periódicos Especializados (PE) foi incorporado pelos indicadores $B B$ e $B C$ nesse novo instrumento.

Nessa nova sistemática de avaliação, os indicadores estão sendo composto pelos seguintes conceitos fundamentais.

I - Objeto de avaliação: indicado por seu título; II - Conceito: valor numérico que representa um nível crescente de qualidade (1 a 5); III - Critério de análise: conjunto de atributos que caracterizam a qualidade do objeto de análise, associados a um conceito; IV - Critério aditivo: atributo suplementar que integra o critério de análise para os conceitos 4 e 5; V - Observação: comentário informativo sobre a aplicação do indicador. (INEP. Nota técnica no 16/2017/CGACGIES/DAES, 2017, p. 4, grifo nosso)

É importante ressaltar que os novos instrumentos consideram que a diferença entre um conceito e outro é determinado pela presença ou aumento da complexidade de um atributo. Os avaliadores in loco buscam essas evidências dos critérios através de observações físicas (observação da infraestrutura), documentais (relatórios expedidos pela biblioteca), testemunhais (entrevistas com a comunidade acadêmica) e analíticas ${ }^{16}$ (obtidas pela comparação, correlação e análise do objeto de avaliação). Essas evidências precisam ter algumas características: suficiência (comprovação da existência), validade (confiabilidade, legalidade), relevância (adequação ao critério de análise) e objetividade (de fácil verificação) (INEP, 2018, p. 41-42). Os critérios deverão ser verificados ou analisados em ordem crescente de atributo, sendo que a existência do critério aditivo não elimina a falta do critério de análise para a obtenção do conceito final do indicador. O critério aditivo só será avaliado com a existência do critério de análise.

Os critérios de análise dos indicadores estão estruturados de forma aditiva a cada elemento e estão sendo avaliados da seguinte forma:

[...] os conceitos 1 e 2 apresentam ausências relativas ao critério de análise do conceito 3 , em torno do qual se caracteriza a suficiência no tocante a cada objeto de avaliação. 0 conceito 4 apresenta critérios aditivos em relação ao conceito 3, e o mesmo ocorre com o conceito 5 , em relação ao 4. (INEP. Nota técnica no 16/2017/CGACGIES/DAES, 2017, p. 4)

Os significados de cada um dos conceitos estão formulados conforme segue:

(1) INSATISFATÓRIO $\rightarrow$ Ausência crítica do objeto de avaliação ou ausência de evidências dos atributos descritos no conceito 2 ou inexistência de evidências que atendam integralmente o disposto no critério de análise do

\footnotetext{
${ }^{16}$ Modalidade de avaliação Institucional: nos descritivos analíticos procura-se comparar ou cruzar variáveis ligadas aos processos internos e aos produtos. (GATTI, Bernadete A. Avaliação Institucional: processo descritivo, analítico ou reflexivo? Estudos em Avaliação Educacional. v. 17, n. 34 maio/ago. 2006. Disponível em: <https://www.fcc.org.br/pesquisa/publicacoes/eae/arquivos /1283/1283.pdf>. Acesso em: 30 set. 2018. DOI: http://dx.doi.org/10.18222/eae173420062115.)
} 
conceito 2; (2) PARCIALMENTE SATISFATÓRIO $\rightarrow$ Ausência de evidências dos atributos descritos no conceito 3 ou inexistência de evidências que não atendam integralmente o disposto no critério de análise do conceito 3; (3) SATISFATÓRIO $\rightarrow$ Existência de evidências para os atributos apresentados nos critérios de análise do conceito 3; I(4) BOM $\rightarrow$ Existência de evidências para os atributos apresentados nos critérios de análise do conceito 3 e para o(s) critério(s) aditivo(s) do conceito 4;

(5) MUITO BOM $\rightarrow$ Existência de evidências para os atributos apresentados nos critérios de análise do conceito 3 e 4 e para o(s) critério(s) aditivo(s) do conceito 5. (INEP. Nota técnica no 2/2018/CGACGIES/DAES, 2018, p. 1)

O conjunto de conceitos avaliativos dos três indicadores (BB, BC e EP) que compõem o ambiente da biblioteca universitária, no instrumento de Avaliação dos Cursos de Graduação, passou a ser dividido conforme o Critério de Análise e o Critério Aditivo de cada indicador.

No entanto, o indicador Periódicos Especializados foi inserido no novo instrumento de avaliação (INEP, 2017) como um critério aditivo aos conceitos da bibliografia básica e da bibliografia complementar, não sendo mais avaliado de forma separada dos dois tipos de bibliografia citados. Tendo em vista sua importância para os conteúdos dos planos de ensino, eles foram classificados também em básicos e complementares, respectivamente como suplemento e complemento.

A seguir, no Quadro 4, apresenta-se um resumo do que consta nos Atos Autorizativos sobre a BB e a BC, mostrando parte por parte o que deverá ser avaliado, bem como a quem cabe a responsabilidade da resposta de cada uma das partes. 
Quadro 4 - Resumo dos Instrumentos de Avaliação para Autorização, Reconhecimento e Renovação de Reconhecimento para a Bibliografia Básica e Complementar

\begin{tabular}{|c|c|c|c|c|c|c|c|c|}
\hline \multicolumn{9}{|c|}{$\begin{array}{l}\text { Indicador 3.6 BIBLIOGRAFIA BÁSICA POR UNIDADE CURRICULAR - } 2017 \\
\text { Indicador 3.7 BIBLIOGRAFIA COMPLEMENTAR POR UNIDADE CURRICULAR - } 2017\end{array}$} \\
\hline \multirow{2}{*}{$\begin{array}{l}\text { Conjunto de } \\
\text { atributos }\end{array}$} & \multirow{2}{*}{ Critério de Análise } & \multicolumn{5}{|c|}{ Conceitos } & \multirow{2}{*}{$\begin{array}{l}\text { O que será } \\
\text { avaliado }\end{array}$} & \multirow{2}{*}{$\begin{array}{l}\text { Responsável } \\
\text { por resposta }\end{array}$} \\
\hline & & 1 & 2 & 3 & 4 & 5 & & \\
\hline \multirow{5}{*}{ 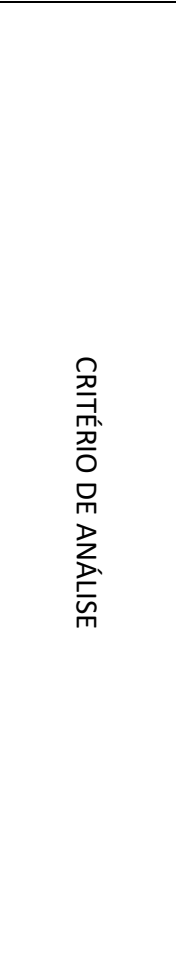 } & O acervo físico está tombado e informatizado, & 丞 & $\frac{n}{3}$ & $\frac{n}{3}$ & $\frac{n}{3}$ & $\frac{n}{3}$ & \multirow{2}{*}{\begin{tabular}{|c|} 
Acervo; \\
Registro; \\
Tombamento; \\
Acesso físico \\
e/ou virtual
\end{tabular}} & \multirow{2}{*}{ 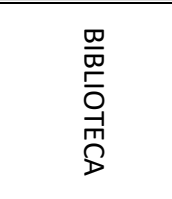 } \\
\hline & $\begin{array}{l}\text { o virtual possui contrato que garante o acesso } \\
\text { ininterrupto pelos usuários e ambos estão } \\
\text { registrados em nome da IES. }\end{array}$ & 㞼 & $\frac{n}{3}$ & $\frac{n}{3}$ & $\frac{n}{3}$ & $\frac{n}{3}$ & & \\
\hline & $\begin{array}{l}\text { O acervo da bibliografia básica é adequado em } \\
\text { relação às unidades curriculares e aos conteúdos } \\
\text { descritos no PPC e está atualizado, } \\
\text { considerando a natureza das UC. }\end{array}$ & 胥 & $\frac{n}{3}$ & $\frac{n}{3}$ & $\frac{\varrho}{3}$ & $\frac{n}{3}$ & $\begin{array}{l}\text { Adequação } \\
\quad \text { da } \\
\text { bibliografia }\end{array}$ & \multirow[b]{2}{*}{ 号 } \\
\hline & $\begin{array}{l}\text { Da mesma forma, está referendado por relatório } \\
\text { de adequação, assinado pelo NDE, } \\
\text { comprovando a compatibilidade, em cada } \\
\text { bibliografia básica da UC, entre o número de } \\
\text { vagas autorizadas (do próprio curso e de outros } \\
\text { que utilizem os títulos) e a quantidade de } \\
\text { exemplares por título (ou assinatura de acesso) } \\
\text { disponível no acervo. }\end{array}$ & 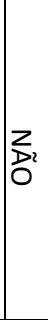 & 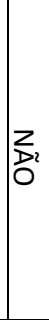 & $\frac{n}{3}$ & $\frac{\cong}{3}$ & $\frac{n}{3}$ & $\begin{array}{l}\text { Compatibili- } \\
\text { dade da } \\
\text { bibliografia } \\
\text { com o } \\
\text { número de } \\
\quad \text { vagas }\end{array}$ & \\
\hline & $\begin{array}{l}\text { Nos casos dos títulos virtuais, há garantia de } \\
\text { acesso físico na IES, com instalações e recursos } \\
\text { tecnológicos que atendem à demanda e à oferta } \\
\text { ininterrupta via internet, bem como de } \\
\text { ferramentas de acessibilidade e de soluções de } \\
\text { apoio à leitura, estudo e aprendizagem. }\end{array}$ & ' & 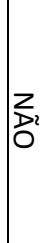 & $\frac{n}{3}$ & $\frac{\cong}{3}$ & $\frac{n}{3}$ & $\begin{array}{l}\text { Acesso ao } \\
\text { acervo } \\
\text { virtual }\end{array}$ & \multirow{3}{*}{ 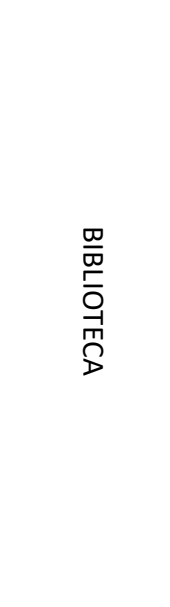 } \\
\hline \multirow{2}{*}{ 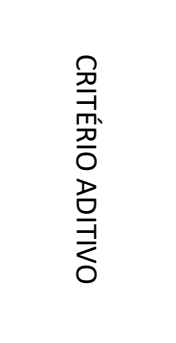 } & $\begin{array}{l}\text { O acervo possui exemplares ou assinaturas de } \\
\text { acesso virtual para periódicos especializados que } \\
\text { suplementam o conteúdo administrado nas UC. }\end{array}$ & 1 & 1 & ' & $\frac{n}{3}$ & $\frac{n}{3}$ & $\begin{array}{c}\text { Periódicos } \\
\text { especializado }\end{array}$ & \\
\hline & $\begin{array}{l}\text { O acervo é gerenciado de modo a atualizar a } \\
\text { quantidade de exemplares e/ou assinaturas de } \\
\text { acesso mais demandadas, sendo adotado plano } \\
\text { de contingência para a garantia do acesso e do } \\
\text { serviço. }\end{array}$ & 1 & 1 & ' & ' & 3 & \begin{tabular}{|} 
Usabilidade \\
do acervo; \\
Plano de \\
Contingência
\end{tabular} & \\
\hline
\end{tabular}

Fonte: Baseado no Instrumento de Avaliação (INEP, 2017a, p. 32-33)

No critério aditivo, o elemento novo é o Plano de Contingência (PC), concebido para assegurar o acesso ao acervo; sua definição vem da área de administrativa, significando um plano de continuidade das atividades organizacionais, caso a instituição entre em colapso; ele tem como objetivo descrever decisões que deverão ser tomadas para recuperar a operacionalização dos processos administrativos e minimizar os prejuízos da organização.

${ }_{17}$ Núcleo Docente Estruturante. 
A biblioteca universitária, nesse contexto, deverá estar contemplada pela Política de Formação e Desenvolvimento de Coleções, onde estará registrado o processo de aquisição de material bibliográfico para atender as demandas dos cursos e eventuais demandas extraordinárias; e também deve expor, em local visível, o modo como a comunidade acadêmica terá acesso ao acervo, se o controle de empréstimo e o acesso eletrônico a ele não estiverem ativos, em caso de desastres físicos (incêndios, quedas de estantes e outros), de greve, de falta de funcionário ou por mudança de horário no atendimento, entre outros eventos que impeçam o usuário de ter acesso à informação.

Nos novos instrumentos de Avaliação dos Cursos de Graduação, houve modificação nos critérios de avaliação quantitativa da $\mathrm{BB}$ e da $\mathrm{BC}$, que passam para um processo qualitativo quanto à adequação dos títulos em relação às ementas das disciplinas e a não determinação de quantitativo de títulos por vaga, alterações estas a serem assumidas pelo Núcleo Docente Estruturante (NDE). (INEP, 2017, p. 1) Na prática, o critério do instrumento anterior (INEP, 2016, p. 40-41), que determinava para o conceito cinco um mínimo de 3 títulos para a bibliografia básica e no mínimo 5 títulos para a complementar (segundo o $\mathrm{n}$. de vagas anuais pretendidas/autorizadas), é uma base que ainda auxilia os bibliotecários e os docentes no processo decisório

O NDE foi criado em pela Portaria no 147, de 2 de fevereiro de 2007, assinada pelo então Ministro da Educação, Fernando Haddad, e "Dispõe sobre a complementação da instrução dos pedidos de autorização de cursos de graduação em direito e medicina [...]". No seu art. 2o, inciso IV, estabelece a "[...] existência de um núcleo docente estruturante, responsável pela formulação do projeto pedagógico do curso, sua implementação e desenvolvimento," [...]. (MEC, Portaria no 147, 2007, p. 1-2, grifo nosso). Sua normalização é feita pela Resolução no 1 , de 17 de junho de 2010, onde a Comissão Nacional de Avaliação da Educação Superior (CONAES) institui as atribuições e a constituição do NDE. Dentre as principais atribuições do NDE, estão:

\footnotetext{
I - contribuir para a consolidação do perfil profissional do egresso do curso; II - zelar pela integração curricular interdisciplinar entre as diferentes atividades de ensino constantes no currículo; III - indicar formas de incentivo ao desenvolvimento de linhas de pesquisa e extensão, oriundas de necessidades da graduação, de exigências do mercado de trabalho e afinadas com as políticas públicas relativas à área de conhecimento do curso; IV - zelar pelo cumprimento das Diretrizes Curriculares Nacionais para os Cursos de Graduação. (BRASIL. Ministério da Educação. CONAES, 2017, p. 1)
}

Em substituição ao indicativo de quantidade de títulos da bibliografia básica e da complementar, expressa no instrumento anterior de avaliação dos cursos de graduação, a responsabilidade desse parâmetro, no instrumento de 2017, foi transferida para o NDE. A ele compete referendar, com um relatório de adequação, a compatibilidade de cada bibliografia básica e complementar da UC, com o número de vagas autorizadas (do próprio curso e de outros 
que utilizem os títulos) e com a quantidade de exemplares por título (ou assinatura de acesso) disponíveis no acervo.

Nesse relatório, o NDE tem a função de realizar uma espécie de 'revisão por pares', avaliando se os títulos indicados no Plano de Ensino evitam: duplicidade de conteúdos, exagero de indicações, desatualização das indicações ou, ainda, se faltam títulos primordiais daquele assunto.

Cabe explicitar que, muitas vezes, a ementa de dada UC requer mais de três títulos na bibliografia básica e mais de cinco na complementar (orientação que era dada no instrumento de avaliação anterior para os cursos de graduação), pois essas quantidades mínimas por vezes não contemplam a totalidade dos assuntos da ementa do curso.

Referendada a adequação dos títulos, o Plano de Ensino é encaminhado para o Colegiado do Curso para aprovação e posterior publicização, visto que na Lei 9.394 de 1996 (Lei de Diretrizes e Bases), art. 47, §1, o governo federal, orienta que "[...] a instituição deverá informar aos interessados, antes de cada período letivo, os programas dos cursos e demais componentes curriculares, sua duração, requisitos, qualificação dos professores, recursos disponíveis e critérios de avaliação, [...]", enfatizado que sua divulgação deverá ser realizada um mês antes do início das aulas.

Nesse contexto, a biblioteca universitária, em sua Política de Desenvolvimento de Coleções, fica sem autonomia quanto à indicação de quantitativos para a aquisição, dificultando o planejamento da aquisição do material bibliográfico: caso o título indicado não tenha no acervo, o NDE deverá indicá-lo para aquisição, além de expor no relatório de adequação a quantidade de exemplares necessária; caso haja o título no acervo, deve ser verificada se a quantidade de exemplares atende a demanda. Parte dessa problemática poderia ser resolvida se a composição do NDE contasse também com um bibliotecário, cuja experiência contribuiria para tomada de decisão do referido Núcleo.

Todas as etapas de Avaliação Institucional e de Avaliação dos Cursos de Graduação são orientadas pela Portaria Normativa no 840 , de agosto de 2018, que dispõe sobre os procedimentos de competência do INEP, referentes ao fluxo avaliativo dos atos autorizativos e regulatórios.

Tomando por base os instrumentos do INEP, todos os processos avaliativos aqui tratados têm a biblioteca alocada simplesmente como um espaço físico, depositário de acervo, e não como um ambiente de transformação de conhecimento. Nesta perspectiva, Lubisco (2014, p. 5) propõe um conceito mais amplo para as bibliotecas universitárias, a saber:

[...] por sua natureza, desempenham um papel fundante na instituição à qual estão ligadas, por sua função de participação no desenvolvimento dos 
programas de ensino, pesquisa e extensão e inovação. Essa função se consubstancia na sua atuação como recurso didático-pedagógico (laboratório de aprendizagem); como plataforma de conhecimento (considerando-a fonte e local de registro da produção técnica e científica da instituição); e como fator de estímulo à formação e ao desenvolvimento do espírito científico.

Ante o exposto, esse ambiente precisa ser avaliado de acordo com as modificações que ele traz para a formação integral da comunidade universitária.

Considerando esse cenário, Lubisco $(2001,2007,2008,2011,2014)$ propõe ainda que a biblioteca passe a constituir uma quarta dimensão no processo avaliativo do INEP, denominada "Biblioteca", alinhada às outras três, quais sejam: a Organização Didático-pedagógico, o Corpo Docente e Tutorial e a Infraestrutura. Nessa proposta, estruturada nos mesmos moldes das outras três dimensões, é possível avaliar, além das bibliografias e dos periódicos, outros elementos pertinentes à biblioteca universitária, quais sejam: seus produtos e serviços, sua infraestrutura tecnológica, sua equipe de colaboradores, sua inserção no planejamento acadêmico, enfim, todo seu universo de atuação. Estima-se que, assim avaliada, ela poderá dispor das condições para revelar o nível de satisfação dos usuários, para proceder à comparação entre bibliotecas do mesmo gênero e para obter os insumos necessários para reformulações do seu planejamento (MANO GONZÁLEZ, 1998, p. 176 apud LUBISCO, 2014, p. 13)

O elenco de itens que integraria a biblioteca como uma quarta dimensão a ser avaliada vem sendo objeto de um estudo em colaboração, a ser materializado num modelo operacional (plataforma web) para avaliação das bibliotecas universitárias, denominado Banco Informações Gerenciais - BIG (LUBISCO, 2014). A referida ferramenta, desse modo, servirá não somente à biblioteca em seus processos de planejamento e gestão, mas à universidade como um todo, pois ela disporá de dados que contribuirão não só para uma avaliação abrangente e consistente da biblioteca, mas para o preenchimento do formulário enviado pelo Ministério da Educação (MEC) antes da visita à instituição; ademais, poderá contribuir para que dados importantes da instituição e das bibliotecas estejam agrupados num único banco de dados, podendo ser utilizados de forma rápida e eficaz para a solução de problemas.

\section{Procedimento metodológico}

Trata-se de uma pesquisa documental, cujas fontes para obtenção das informações e dos dados foram as páginas web do INEP ${ }^{18}$, da Comissão Própria de Avaliação da UFBA ${ }^{19}$ e da

\footnotetext{
$18<$ http://portal.inep.gov.br/web/guest/educacao-superior $>$

${ }^{19}<$ https://www.cpa.ufba.br/relatorios-inep/cursos>
} 
Superintendência de Avaliação e Desenvolvimento Institucional/Coordenação de Avaliação/Cursos ${ }^{20}$.

Além dos aspectos histórico-conceituais, baseados na literatura pertinente constitutiva do referencial teórico, identificaram-se e analisaram-se 83 relatórios em Portable Document Format - PDF (Formato Portátil de Documento), referentes às visitas in loco realizadas por ocasião dos processos de Autorização, Reconhecimento e Renovação de Reconhecimento dos Cursos de Graduação, da Universidade Federal da Bahia, entre os anos de 2010 a início de 2017, pelas comissões de avaliação do INEP.

Esses relatórios foram emitidos a partir dos Instrumentos de Avaliação dos Cursos de Graduação - presencial e a distância (2015) que à época subsidiava “[...] a autorização, reconhecimento e renovação de reconhecimento - nos graus de tecnólogo, de licenciatura e de bacharelado para a modalidade presencial e a distância." (INEP. Instrumento..., 2015, p. 2.). Portanto, para o novo Instrumento de Avaliação dos Cursos de Graduação de 2017, houve modificações nos cálculos para a avaliação das Bibliografias Básica e Complementar e dos Periódicos Especializados.

Os critérios de avaliação, considerando as bibliotecas bibliografias básicas, as bibliografias complementares e os periódicos especializados, segundo o INEP (2015), visando à obtenção da nota máxima - conceito 5 - era necessário que a bibliografia básica (BB) dispusesse de três títulos por disciplina, na proporção de um exemplar para menos de cinco vagas anuais, de cada uma das disciplinas de todos os cursos que utilizassem o acervo. Para o indicador bibliografia complementar (BC) obter a nota 5, o acervo deveria contar com, pelo menos, cinco títulos por disciplina, "[...] com dois exemplares de cada título ou com acesso virtual" (INEP, 2015). Quanto aos periódicos especializados (PE), a nota máxima ocorria quando houvesse assinaturas com acesso à forma impressa ou virtual, maior ou igual a 20 títulos com acervo atualizado (INEP, 2015).

Utilizou-se o aplicativo Excel da Microsoft para lançar e organizar os dados e, assim, facilitar a sua análise.

Iniciou-se por identificar quais dados precisariam ser coletados e, logo, procedeu-se ao seu ordenamento por categorias para possibilitar a sua correlação, visando às conclusões e inferências que seguem.

Foram reunidos 83 relatórios, relativos a todas as avaliações efetuadas no período (2010-2017), analisando-se minuciosamente o que concerne aos indicadores considerados pelo INEP para a avaliação da biblioteca universitária.

$20<$ htpp://supad.ufba.br/relatório-inep-cursos> 


\section{Análise e interpretação dos dados}

De acordo com o levantamento feito para este estudo, vários cursos da UFBA foram criados em decorrência do projeto REUNI. Com isto, pode-se notar que, pela passagem de 4 a 6 anos desde as respectivas Autorizações, grande número deles passou pelo processo de Reconhecimento, no período entre 2011 e 2015. O Gráfico 1 mostra os cursos avaliados na UFBA, registrando principalmente o Reconhecimento de novos cursos (ano de 2014) oriundos do projeto REUNI.

Gráfico 1 - Total de 83 Cursos de Graduação da UFBA avaliados entre os anos de 2010-2017 por ato regulatório.

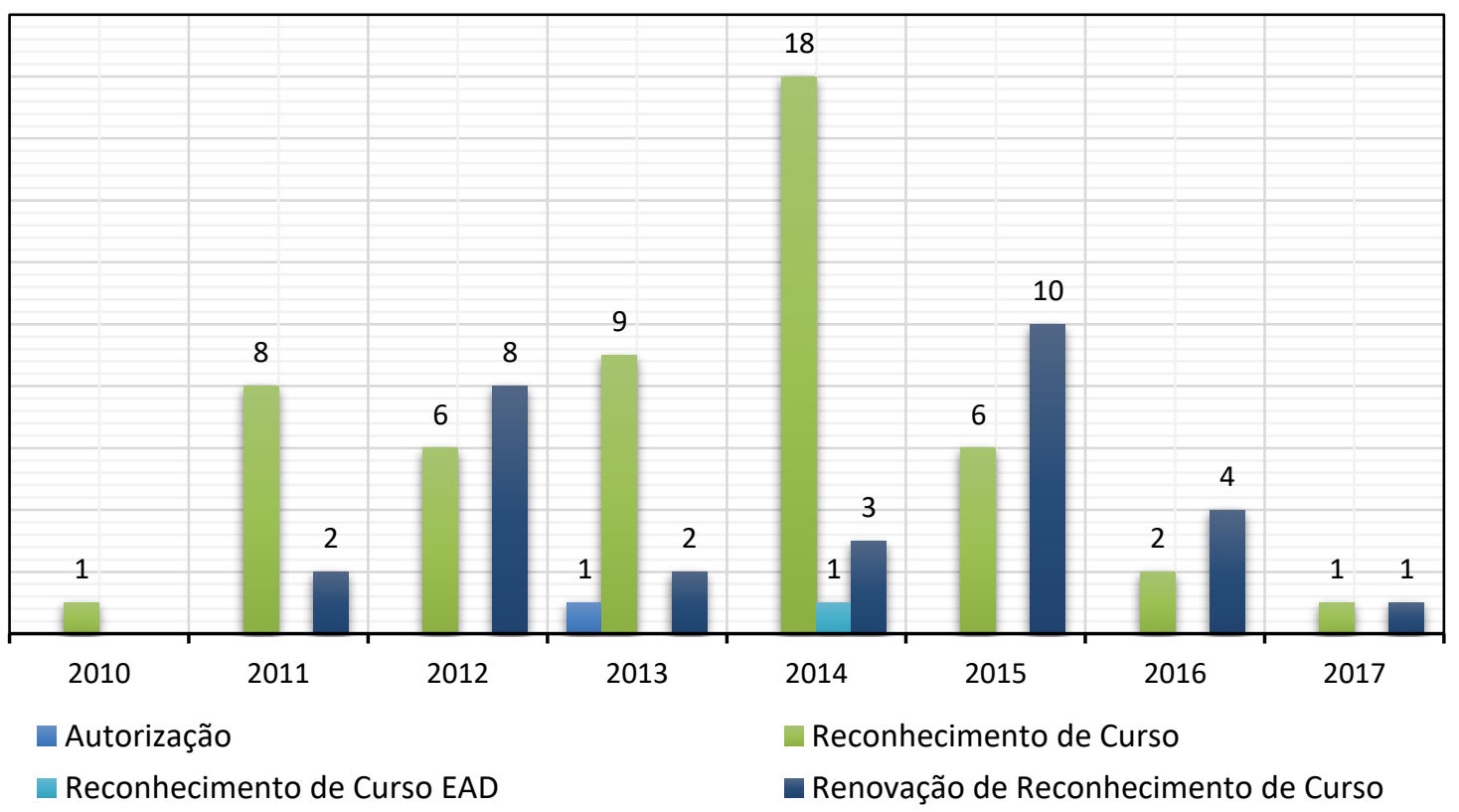

Fonte: Dados da pesquisa.

Nota-se que o maior índice foi de Reconhecimento de Curso (51 cursos), ou seja, criaram-se novas vagas de graduação na UFBA, com ênfase para os cursos noturnos. Em 2017, a UFBA contava com um total de 107 cursos de graduação ${ }^{21}$, os quais passaram por avaliação in loco quando os alunos não atingiram nota 3 (três) ou mais no Exame Nacional de Desempenho do Estudante (Enade).

${ }^{21}<$ https://siac.ufba.br/> 
Gráfico 2 - Reconhecimento de cursos relacionado com os turnos na UFBA.

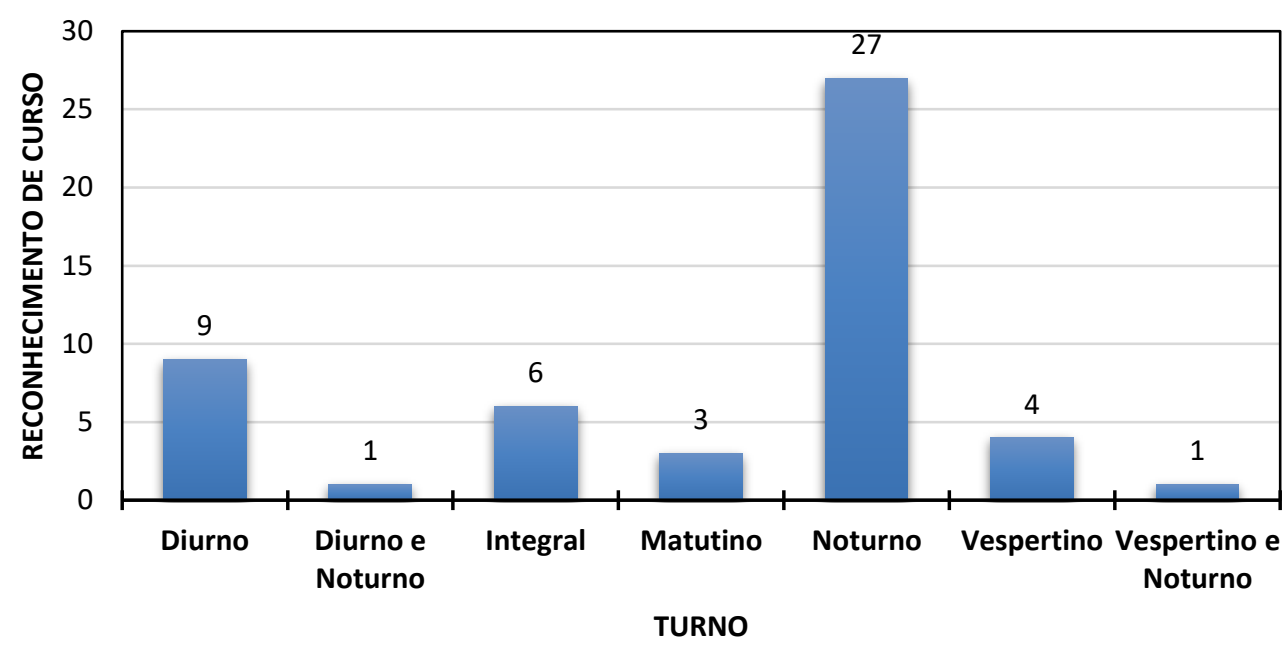

Fonte: Dados da pesquisa.

A indicação dos turnos no Gráfico 2 foi retirada dos relatórios das Avaliações in loco dos cursos avaliados. De acordo com o boletim de estatística da UFBA, Retrospectiva - Especial 70 anos, o total de cursos noturnos passou de 1 para 31 cursos, entre os anos de 2006 a 2015, tendo o número de vagas aumentado de 40 para 2.370. O número de inscritos teve um aumento de 153 para 65.177. O ano que teve a maior criação de cursos foi 2010, segundo as estatísticas da Universidade. (UNIVERSIDADE FEDERAL DA BAHIA, 2016, p. 10).

Gráfico 3 - Relação do Ato autorizativos com o crescimento das Avaliações do INEP por Áreas dos Cursos de Graduação da UFBA, entre os anos de 2010-2017.

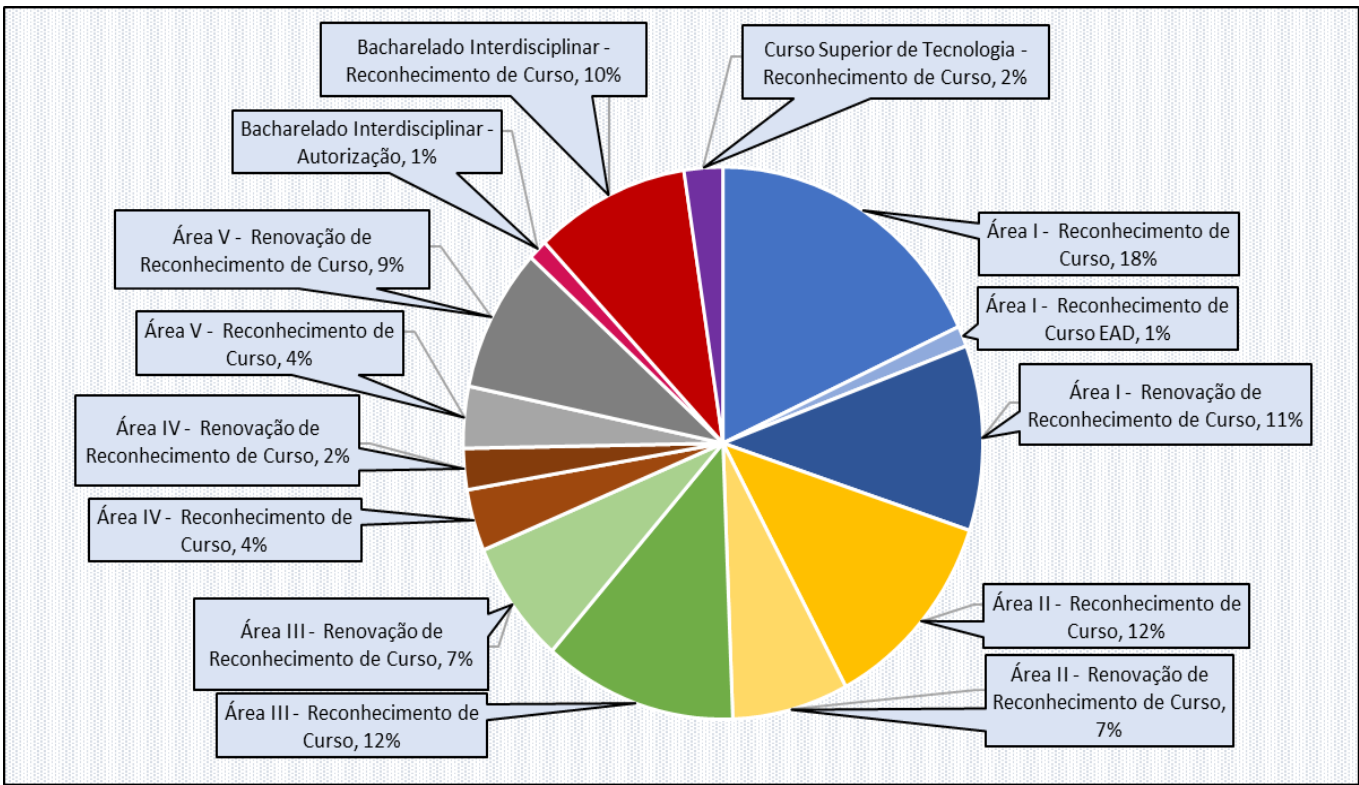

Fonte: Dados da pesquisa.

Legenda: Área I: Ciências Físicas, Matemática e Tecnologia; Área II: Ciências Biológicas e Profissões de Saúde; Área III: Filosofia e Ciências Humanas; Área IV: Letras; Área V: Artes; Instituto de Humanidades, Artes e Ciências (Bacharelado Interdisciplinar); Curso Superior de Tecnologia. 
A UFBA distribui seus cursos de graduação em sete áreas, para fins da organização administrativa, acadêmico-pedagógica e financeira da Universidade. No Gráfico 3, expõe-se o crescimento da Avaliação do INEP em relação a essas áreas e demonstra-se o crescimento da área I, seguida da área II. Na área I, houve maior crescimento de novas vagas e renovação das vagas na UFBA, entre os anos de 2011 e 2017.

O Gráfico 4 apresenta um resumo dos anos avaliados e indica a evolução das notas finais.

Gráfico 4 - Conceitos atribuídas aos 83 cursos de graduação da UFBA, avaliados entre 2010 e 2017, por quantidade de curso

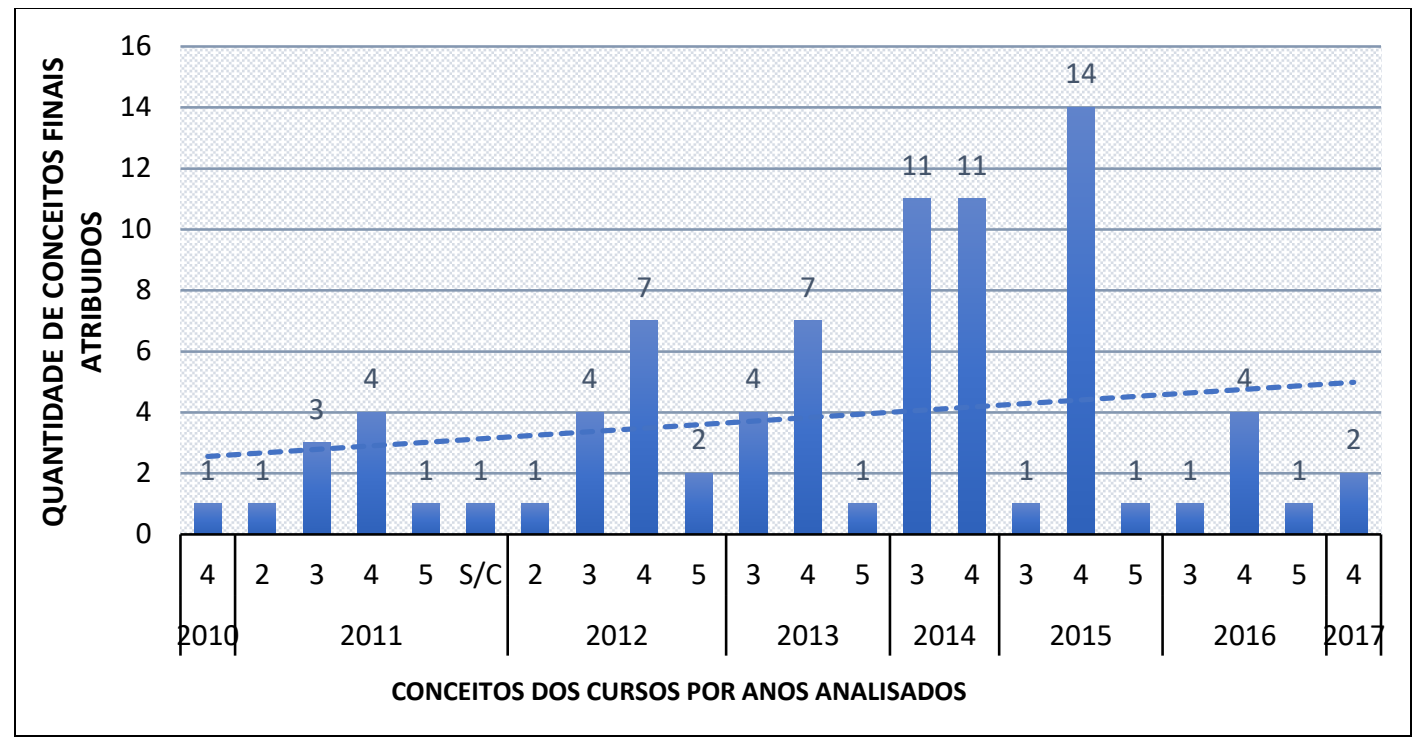

Fonte: Dados da pesquisa.

Legenda: Os numerais de 2 a 5 correspondem às notas; $S / C=$ Sem Conceito.

As bibliotecas da UFBA, neste contexto, não seguem a mesma tendência de crescimento que se observa nos cursos indicados no Gráfico 4, pois nos cálculos do conceito final observa-se que aqueles Indicadores relacionados a elas não influenciam no resultado: dos 83 cursos analisados, 3 receberam conceito 1 nos 3 indicadores (BB, BC e PE), mas ficaram com a nota final 3 e 4, portanto, muito próximas à nota máxima - 5 (Quadro 2). 
Quadro 5 - Conceito Máximo da Dimensão 3 (Infraestrutura), comparando com os Conceito Mínimo da Bibliografia Básica,

Bibliografia Complementar e Periódico Especializados.

\begin{tabular}{|c||c||c||c||c||c||c|}
\hline $\begin{array}{c}\text { CONCETO DA } \\
\text { BIBLIOGRAFA } \\
\text { BÁSICA }\end{array}$ & $\begin{array}{c}\text { CONCETO DA } \\
\text { BIBLIOGRAFIA } \\
\text { COMPLEMENTAR }\end{array}$ & $\begin{array}{c}\text { CONCETO DOS } \\
\text { PERIÓDICOS }\end{array}$ & DIMENSÃO3 & NOTA FINAL & $\begin{array}{c}\text { ANO DA } \\
\text { AVALIAÇÃO }\end{array}$ & $\begin{array}{c}\text { CÓDIGO DE } \\
\text { AVALIAÇÃO }\end{array}$ \\
\hline \hline 1 & 1 & 1 & 2,9 & 3 & 2014 & 108608 \\
\hline \hline 1 & 1 & 1 & 3,3 & 4 & 2012 & 94207 \\
\hline \hline 1 & 1 & 1 & 4,0 & 4 & 2011 & 89802 \\
\hline \hline 2 & 2 & 2 & 2,1 & 3 & 2012 & 93457 \\
\hline \hline 2 & 2 & 2 & 2,0 & 4 & 2014 & 89183 \\
\hline \hline 3 & 3 & 3 & 3,0 & 2 & 2011 & 89184 \\
\hline \hline 4 & 4 & 4 & 3,1 & 2 & 2012 & 93169 \\
\hline 5 & 5 & 5 & 4,1 & 3 & 2013 & 103258 \\
\hline
\end{tabular}

Fonte: Dados da pesquisa.

Ademais, a priori, surpreendem as notas de 1 a 4 atribuídas ao indicador Periódicos Especializados, ao considerar-se que todas as bibliotecas da UFBA têm acesso ao Portal da Capes (Tabela 1). No entanto, numa análise mais acurada, há dois fatores a considerar: 1) comumente, nos Planos de Ensino dos cursos de graduação da UFBA não se incluem periódicos especializados - mais afetos aos cursos de pós-graduação; 2) e, caso algum docente, na sua prática, adote um ou mais títulos para a graduação, não faz constar no referido Plano. Com isto, um curso bem avaliado na dimensão 3 (Infraestrutura), como demonstra o Gráfico 4, pode perfeitamente ter nota 1 no Indicador Periódicos Especializados. No entanto, este conceito mínimo não repercute no conceito final da dimensão Infraestrutura, uma vez que o três Indicadores relativos à Biblioteca (BB, BC e PE) "competem" em condições de igualdade entre si e com mais 20 indicadores (INEP, 2016 p. 51), como dito anteriormente.

Resposta enviada por e-mail por parte do INEP (Coordenação-Geral de Avaliação dos Cursos de Graduação e IES - CGACGIES) a uma das autoras, em 22 de agosto de 2017, pelo protocolo n. 2784301, referente à pergunta sobre qual o peso dos indicadores Bibliografia Básica e Complementar no cálculo da dimensão Infraestrutura:

O conceito do curso (CC) é calculado, pelo sistema e-MEC, com base na média aritmética ponderada dos conceitos das dimensões, os quais são resultados da média aritmética simples dos indicadores das respectivas dimensões. Não há pesos atribuídos aos indicadores.

Esta situação é um dos pontos críticos que vimos levantando em relação à adequação e suficiência dos indicadores dos INEP e que reforça nossa posição de que a biblioteca universitária venha a constituir-se numa quarta dimensão a ser avaliada, de modo que seu desempenho, de um lado, contribua efetivamente na nota final não só da Dimensão, mas do curso como um todo; 
de outro, que a biblioteca seja representada com fidedignidade no seu desempenho - para o bem e para o mal - e assim forneça aos gestores os elementos necessários para sua melhoria no cumprimento do seu papel dentro da academia e para justificar os investimentos feitos e demandados.

Quanto ao Portal de Periódicos da Capes, teoricamente influente no indicador Periódicos Especializados, teve início em 1990, sendo oficializado em 2000, com o objetivo de solidificar o uso do formato eletrônico das coleções científicas para as Instituições de Ensino Superior. Com essa iniciativa, a Capes passou a centralizar a compra de assinaturas dos periódicos especializados, liberando as universidades desse encargo, sendo que elas mantiveram, segundo seu interesse, as assinaturas dos periódicos impressos.

O Gráfico 5, aparentemente, revela a desconsideração acerca do objetivo de criação e do conteúdo do Portal de Periódicos da Capes, por parte dos avaliadores, ou das instruções que o Indicador coloca para cada conceito, visto que dos 83 cursos avaliados só 46 cursos receberam conceito máximo (5) no Indicador Periódicos Especializados.

Gráfico 5 - Nota do Indicador Periódicos Especializados, relacionada com o Conceito Final nos 83 cursos avaliados.

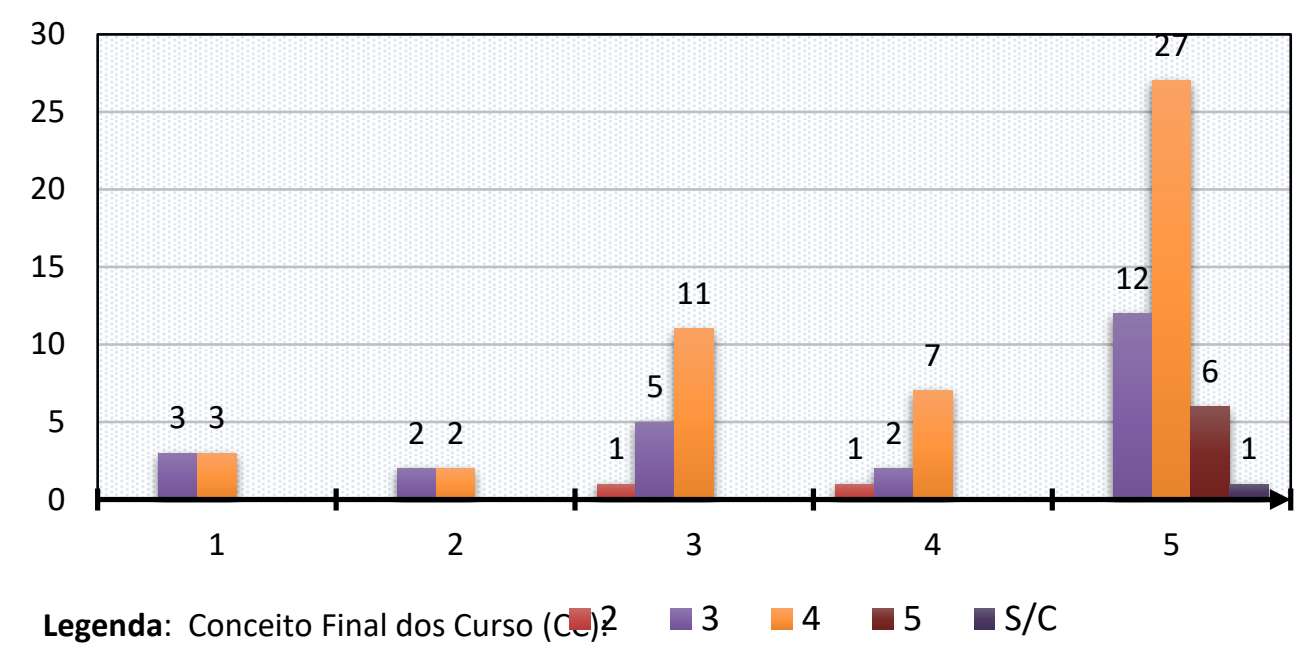

Fonte: Dados da pesquisa.

Legenda: O eixo horizontal corresponde aos conceitos atribuídos pelos avaliadores ao Indicador Periódicos Especializados. O eixo vertical corresponde à quantidade de cursos por Conceito final de Curso.

Além disso, um dos relatórios de Avaliação in loco, com conceito 4 no Indicador Periódicos Especializados, tem uma justificativa improcedente, visto que o Portal de Periódico da Capes deveria atender a todos os critérios da nota máxima do indicador, e na justificativa os avaliadores pontuaram que um periódico criado pelo curso está classificado pelo WebQualis no 
estrato B-2, como se esta classificação influenciasse na nota do indicador. Não há a menor razão, se isto ocorreu de fato. Segue a justificativa do avaliador:

A IES mantém assinaturas de 15 periódicos especializados indexados e correntes, sob forma impressa ou virtual, cujos títulos encontram-se distribuídos entre as principais áreas do curso, a maioria deles com acervo atualizado em relação aos últimos três anos. Além destes, a IES possui uma revista intitula-se "Cultura Visual" e possui classificação Qualis B-2. Também são disponibilizados artigos de periódicos especializados como Arco Design, por exemplo, entre outros. (INEP, avaliação n. 128678, 2017)

Para ilustrar as inconsistências atribuídas ao Indicador Periódicos Especializados, por parte dos avaliadores, selecionaram-se 28 cursos (34\%) que citavam explicitamente os Periódicos para justificar o conceito por eles atribuídos.

Quadro 6 - Justificativa dos conceitos dados pelos avaliadores aos Periódicos Especializados

\begin{tabular}{|c|c|c|c|}
\hline $\begin{array}{c}\text { ANO DA } \\
\text { AVALIAÇÃO }\end{array}$ & $\begin{array}{l}\text { CÓDIGO DE } \\
\text { AVALIAÇÃO }\end{array}$ & $\begin{array}{l}\text { CONCEITO } \\
\text { DOS } \\
\text { PERIÓDICOS }\end{array}$ & JUSTIFICATIVA DOS PERIÓDICOS ESPECIALIZADOS \\
\hline 2010 & 84462 & 4 & $\begin{array}{l}\text { Os periódicos indexados e correntes podem ser } \\
\text { acessados pela sede, a biblioteca do campus, por } \\
\text { não estar informatizada ainda não possui qualquer } \\
\text { sistema de consulta. Os periódicos abrangem as } \\
\text { principais áreas temáticas e estão distribuídos entre } \\
\text { as principais áreas do curso. }\end{array}$ \\
\hline 2011 & 89206 & 2 & $\begin{array}{l}\text { A biblioteca da IES dispõe de periódicos eletrônicos } \\
\text { na base da CAPES. }\end{array}$ \\
\hline 2011 & 89802 & 1 & $\begin{array}{l}\text { Quanto aos livros da bibliografia complementar e } \\
\text { aos periódicos especializados, sob a forma impressa } \\
\text { ou informatizada, atendem precariamente as } \\
\text { demandas do curso. }\end{array}$ \\
\hline 2012 & 93168 & 3 & $\begin{array}{l}\text { O acesso aos periódicos especializados, indexados e } \\
\text { correntes, sob a forma impressa ou virtual, é maior } \\
\text { que } 10 \text { títulos distribuídos entre as principais áreas } \\
\text { do curso, a maioria deles com acervo atualizado em } \\
\text { relação aos últimos } 3 \text { anos. }\end{array}$ \\
\hline 2012 & 93170 & 1 & $\begin{array}{l}\text { Não há assinaturas de revistas e periódicos } \\
\text { especializados em Design nem a presença de filmes, } \\
\text { vídeos, CD-ROM ou mídias digitais relevantes para a } \\
\text { formação do acadêmico. No entanto, há } \\
\text { disponibilidade de acesso ao portal de periódicos da } \\
\text { CAPES com material especializado, indexado e } \\
\text { atualizado em todas as áreas de conhecimento. }\end{array}$ \\
\hline 2012 & 90106 & 3 & $\begin{array}{l}\text { 3.5. Conceito referencial mínimo de qualidade } \\
\text { atendido. Constatou-se que UFBA possui acesso ao } \\
\text { portal de periódicos da CAPES. Além disso, O } \\
\text { Programa de Pós-Graduação em Teatro da } \\
\text { instituição publica um periódico classificado na área } \\
\text { de Artes, pelo Qualis Capes, como A2 }\end{array}$ \\
\hline 2012 & 93169 & 4 & $\begin{array}{l}\text { Há assinaturas de periódicos especializados através } \\
\text { do Portal de Periódicos CAPES. }\end{array}$ \\
\hline
\end{tabular}




\begin{tabular}{|c|c|c|c|}
\hline 2012 & 92781 & 3 & $\begin{array}{l}\text { Em relação aos periódicos, além dos números } \\
\text { disponibilizados fisicamente, há a possibilidade de } \\
\text { acessar o Portal da Capes. }\end{array}$ \\
\hline 2012 & 93457 & 2 & $\begin{array}{l}\text { Apesar dos alunos poderem acessar os periódicos } \\
\text { disponibilizados pelo Portal Capes, a biblioteca não } \\
\text { possui assinatura de outros periódicos } \\
\text { especializados. }\end{array}$ \\
\hline 2012 & 93660 & 1 & $\begin{array}{l}\text { Os periódicos especializados são inexpressivos e } \\
\text { somam uma coleção retrospectiva. A Biblioteca } \\
\text { Reitor Macedo Costa optou por suspensão de todas } \\
\text { as assinaturas de periódicos, uma vez que segundo } \\
\text { a bibliotecária em exercício, existe o Portal da } \\
\text { Capes. A comissão observou que tanto a direção } \\
\text { quanto o corpo docente faz menção ao problema, } \\
\text { pois o acervo disponivel não atende de forma } \\
\text { suficiente as demandas de periódicos solicitadas } \\
\text { pelo curso. }\end{array}$ \\
\hline 2013 & 96667 & 3 & $\begin{array}{l}\text { A biblioteca apresentou somente assinaturas de } \\
\text { periódicos virtuais via Portal CAPES. }\end{array}$ \\
\hline 2013 & 96275 & 3 & $\begin{array}{l}\text { Existe assinatura/acesso de periódicos } \\
\text { especializados, indexados e correntes, sob a forma } \\
\text { virtual, em número maior ou igual a } 10 \text { e menor que } \\
15 \text { títulos distribuidos entre as principais áreas do } \\
\text { curso, a maioria deles com acervo atualizado em } \\
\text { relação aos últimos } 3 \text { anos. }\end{array}$ \\
\hline 2013 & 92788 & 3 & $\begin{array}{l}\text { A biblioteca tem acesso ao portal Capes e há vários } \\
\text { periódicos digitais na área de Letras. }\end{array}$ \\
\hline 2014 & 107881 & 1 & $\begin{array}{l}\text { Há assinatura/acesso de periódicos especializados, } \\
\text { indexados e correntes através do Portal Capes de } \\
\text { Periódicos. }\end{array}$ \\
\hline 2014 & 89183 & 2 & $\begin{array}{l}\text { Existem: assinaturas de periódicos especializados, } \\
\text { indexados e correntes, sob a forma impressa ou } \\
\text { informatizada; bases de dados específicas (revistas } \\
\text { e acervo em multimídia), que atendem muito bem } \\
\text { aos programas de todos os componentes } \\
\text { curriculares e à demanda do conjunto dos alunos } \\
\text { matriculados no curso. }\end{array}$ \\
\hline 2014 & 105076 & 3 & $\begin{array}{l}\text { Com relação aos periódicos especializados, fo } \\
\text { observado em forma impressa (mais antigos) e nas } \\
\text { bases de dados digitais como o Portal de Periódicos } \\
\text { da CAPES. }\end{array}$ \\
\hline 2014 & 108783 & 3 & $\begin{array}{l}\text { Os periódicos especializados há assinatura/acesso } \\
\text { de periódicos especializados, indexados e correntes, } \\
\text { sob a forma impressa ou virtual, maior ou igual a } 10 \\
\text { e menor que } 15 \text { títulos distribuídos entre as } \\
\text { principais áreas do curso, a maioria deles com } \\
\text { acervo atualizado em relação aos últimos } 3 \text { anos. }\end{array}$ \\
\hline 2014 & 108781 & 4 & $\begin{array}{l}\text { "Há indicação de assinatura de periódicos } \\
\text { eletrônicos." }\end{array}$ \\
\hline 2014 & 112651 & 3 & $\begin{array}{l}\text { A Bibliografia possui, através do Portal CAPES, } \\
\text { acesso aos periódicos especializados da área. O } \\
\text { portal de Periódicos CAPES pode ser consultado na } \\
\text { biblioteca. Caso o usuário tenha uma conexão VPN } \\
\text { fornecida pela IES de acordo com política própria } \\
\text { poderá acessar o Portal de outros locais. }\end{array}$ \\
\hline
\end{tabular}




\begin{tabular}{|c|c|c|c|}
\hline 2014 & 102389 & 4 & $\begin{array}{l}\text { Os periódicos especializados sob a forma impressa } \\
\text { ou informatizada estão atualizados em sua maioria } \\
\text { nos últimos três anos, abrangem as principais áreas } \\
\text { temáticas e estão distribuídos entre as principais } \\
\text { áreas do curso. }\end{array}$ \\
\hline 2014 & 108608 & 1 & $\begin{array}{l}\text { Não há assinatura de periódicos especializados } \\
\text { impressos, a consulta se faz apenas de modo digital, } \\
\text { por meio do acesso ao portal da Capes e ao Scielo. }\end{array}$ \\
\hline 2014 & 94310 & 3 & $\begin{array}{l}\text { Há assinatura/acesso de periódicos especializados, } \\
\text { indexados e correntes, sob a forma virtual ou } \\
\text { impressa maior ou igual a } 10 \text { e menor que } 15 \text { títulos } \\
\text { distribuídos entre as principais áreas do curso, a } \\
\text { maioria deles com acervo atualizado em relação aos } \\
\text { últimos } 3 \text { anos. }\end{array}$ \\
\hline 2014 & 107888 & 3 & $\begin{array}{l}\text { Constata-se que a IES disponibiliza um link na } \\
\text { página virtual para acesso a vários periódicos } \\
\text { virtuais nas várias áreas do conhecimento, os quais } \\
\text { podem ser acessados por toda a comunidade } \\
\text { acadêmica de forma doméstica, por meio da } \\
\text { plataforma. }\end{array}$ \\
\hline 2014 & 107890 & 4 & $\begin{array}{l}\text { A UFBA proporciona aos alunos acesso a vários } \\
\text { periódicos na forma virtual, especialmente pelo } \\
\text { acesso ao Portal CAPES de Periódicos. }\end{array}$ \\
\hline 2015 & 109142 & 4 & $\begin{array}{l}\text { Por outro lado, constatou-se na biblioteca a } \\
\text { existência de assinaturas e acesso de periódicos } \\
\text { especializados, indexados e correntes, sob a forma } \\
\text { impressa ou virtual, atualizado em relação aos } \\
\text { últimos } 3 \text { anos. }\end{array}$ \\
\hline 2015 & 104853 & 4 & $\begin{array}{l}\text { Há um espaço próprio para periódicos físicos, cujas } \\
\text { assinaturas foram suspensas, pois a instituição só } \\
\text { tem adquirido periódicos virtuais, como por } \\
\text { exemplo, a plataforma da Capes. }\end{array}$ \\
\hline 2015 & 115686 & 4 & $\begin{array}{l}\text { A Biblioteca dá acesso ao Portal de Periódicos } \\
\text { Capes, o que possibilita aos alunos e ao corpo } \\
\text { docente a disponibilidade de um acervo expressivo } \\
\text { de periódicos especializados na área. }\end{array}$ \\
\hline 2015 & 108782 & 3 & $\begin{array}{l}\text { Existe acesso de periódicos especializados, } \\
\text { indexados e correntes, soba forma virtual, maior e } \\
\text { menor que } 15 \text { títulos distribuídos entre as principais } \\
\text { áreas do curso, a maioria deles com acervo } \\
\text { atualizado em relação aos últimos } 3 \text { anos. }\end{array}$ \\
\hline 2016 & 121847 & 4 & $\begin{array}{l}\text { O Portal da Capes é ferramenta preciosa para os } \\
\text { periódicos especializados e a instituição tem o } \\
\text { acesso. }\end{array}$ \\
\hline
\end{tabular}

Fonte: Dados da pesquisa.

Outro aspecto que surpreendeu nos relatórios examinados foi o resultado da avaliação 121807 (número atribuído pelo INEP). Consta no relatório tomado como exemplo, quanto à Bibliografia Básica: “Pela amostragem feita, verificou-se que existe um exemplar para 7 vagas autorizadas" (grifo nosso). Ora, a Bibliografia Básica, que deve constar no Plano de Ensino, é avaliada por unidade curricular (disciplina). Pergunta-se: Como o avaliador pôde avaliar a 
Bibliografia Básica por amostragem, se o conceito a ser atribuído a ela foi calculado pela média do total dos exemplares do Curso? Neste caso, pode-se considerar que houve um equívoco do avaliador quanto ao entendimento das Instruções para Preenchimento do Formulário e-MEC.

Ainda quanto aos resultados, cujas evidências sugerem subjetividade ou mesmo má interpretação por parte dos avaliadores, foram encontradas também argumentações referentes a aspectos não solicitados pelo instrumento de avaliação do INEP, como se pode observar em alguns exemplos que seguem:

A Instituição tem uma Biblioteca Central, com 4 andares para os cursos da saúde, bem iluminada e ventilada. $O$ acervo tem um sistema informatizado que possibilita consulta e reserva via internet. Tem 55 mesas para leitura e 12 cabines individuais. Não tem salas de reunião para pequenos grupos. (INEP, avaliação n. 113129, 2015).

Na visita in loco na Biblioteca do curso de Química verificou-se um número razoável de livros para os dois primeiros anos do curso, considerando 40 vagas semestrais de entrada de alunos. Na visita in loco na Biblioteca do curso foi verificado existir um número razoável de bibliografia complementar para os alunos do curso. (INEP, avaliação n. 121847, 2016).

Biblioteca setorial dispõe de um acervo numeroso, porém muito desatualizado. Parece não existir uma sistemática de atualização dos livros, em especial de áreas específicas. (INEP, avaliação n. 86806, 2011).

Reiterando o parágrafo anterior, os itens 3 e 4 das Instruções para Preenchimento (INEP, 2015, p. 1) orientam o avaliador a:

3. Atribuir os conceitos a cada um dos indicadores. Os conceitos deverão ser justificados, com argumentação qualitativa e contextualizados, com base nos indicadores.

4. Assegurar a coerência dos conceitos atribuídos aos indicadores com as suas respectivas justificativas (análise quantitativa e análise qualitativa).

\section{Conclusões e recomendações}

Por oportuno, conclui-se que os casos de avaliação inadequada, anteriormente indicados, não excluem os casos exitosos, em que os cursos, em todos os seus aspectos, inclusive nos Indicadores que representam a biblioteca, foram avaliados de forma fidedigna à realidade conhecida, segundo os critérios do INEP. No entanto, diante dos novos instrumentos vigentes a partir de 2017, em processo de análise pelas autoras, permanece a situação que vem permeando esses estudos desde 2001: a inadequação e insuficiência de indicadores para representar a biblioteca de forma ampla, no cumprimento de suas funções dentro de uma instituição de ensino superior.

O que se quer, assim, é que a biblioteca universitária seja transformada numa quarta dimensão a ser avaliada - ao lado da Organização Didático-Pedagógica, do Corpo Docente e Tutorial e da Infraestrutura -, na perspectiva de que, por um lado, ela tenha representatividade 
no total da avaliação por sua função de estrutura fundante da Instituição; por outro, que uma avaliação fidedigna de seu status quo venha promover seu constante aperfeiçoamento, na oferta de serviços e produtos pertinentes ao desenvolvimento dos programas de ensino e de pesquisa da Universidade, o que não ocorre quando apenas as bibliografias básicas e complementares e os periódicos são levados em consideração. (LUBISCO, 2017)

\section{Referências}

BARBOSA, Marilene L. A; FRANKLIN, Sérgio. Controle, avaliação e qualidade de serviço em unidades de informação. In: LUBISCO, Nídia M. L. (Org.). Biblioteca universitária: elementos para o planejamento, avaliação e gestão. Salvador: EDUFBA, 2011. p. 89-137.

BELLONI, Isaura. Avaliação da universidade: por uma proposta de avaliação consequente e compromissada política e cientificamente. In: FÁVERO, Maria de Lourdes. (Org.) A universidade em questão. São Paulo: Cortez; Autores Associados, 1989.

BRASIL. Decreto no 9.235 de 15 de dezembro 2017. Dispõe sobre o exercício das funções de regulação, supervisão e avaliação das instituições de educação superior e dos cursos superiores de graduação e de pós-graduação no sistema federal de ensino. Diário Oficial [da] República Federativa do Brasil. Poder Legislativo. Brasília, DF, 18.dez. 2017. Disponível em: <http://www.planalto.gov.br/ccivil_03/_Ato2015-2018/2017/Decreto/D9235.htm>. Acesso em: 10 abr. 2017.

BRASIL. Lei no 9.394, de 20 de dezembro de 1996. Estabelece as diretrizes e bases da educação nacional. Diário Oficial [da] República Federativa do Brasil, Brasília, DF, 23 dez. 1996. Disponível em: <http://www.planalto.gov.br/ccivil_03/LEIS/I9394.htm>. Acesso em: 02 fev. 2018.

BRASIL. Lei no 10.861, de 14 de abril de 2004. Institui o Sistema Nacional de Avaliação da Educação Superior - SINAES e dá outras providências. Diário Oficial [da] República Federativa do Brasil, Poder Legislativo, Brasília, DF, 15 abr. 2004. Disponível em: <http://www.planalto.gov.br/ccivil/_Ato2004-2006/2004 /Lei/L10.861.htm>. Acesso em: 10 abr. 2017.

BRASIL. Lei no 11.892, de 29 de dezembro de 2008. Institui a Rede Federal de Educação Profissional, Científica e Tecnológica, cria os Institutos Federais de Educação, Ciência e Tecnologia, e dá outras providências. Diário Oficial [da] República Federativa do Brasil, Brasília, DF, 29 dez. 2008. Disponível em: <http://www.planalto.gov.br/ccivil_03/_ato20072010/2008/lei/l11892.htm>. Acesso em: 02 fev. 2018.

BRASIL. MINISTÉRIO DA EDUCAÇÃO. Portaria normativa no 840, de 24 de agosto de 2018. Dispõe sobre os procedimentos de competência do Instituto Nacional de Estudos e Pesquisas Educacionais Anísio Teixeira, referentes à avaliação de instituições de educação superior, de cursos de graduação e de desempenho acadêmico de estudantes. Diário Oficial [da] República Federativa do Brasil, Brasília, DF, Seção 1, no 165, p. 99-102, 27 ago. 2018. Disponível em: $<$ http://download.inep.gov.br/educacao_superior/avaliacao_institucional/legislacao_normas/ 2018/portaria_normativa_GM-MEC_n840_de_24082018.pdf̄. Acesso em: 02 set. 2018.

BRASIL. MINISTÉRIO DA EDUCAÇÃO. Comissão Nacional de Avaliação da Educação Superior. Resolução no 01, de 17 de junho de 2010. Normatiza o Núcleo Docente Estruturante e dá outras providências. Brasília, DF, 2010. Disponível em: <http://portal.mec.gov.br/index.php ?option=com_docman\&task=doc_download\&gid=6885\&ltemid=>. Acesso em: 02 set. 2018.

BUTLER, Pierce. Introdução à ciência da biblioteconomia. Rio de Janeiro: Lidador, 1971. 86p. 
CAMPELLO, Bernadete Santos; CENDÓN, Beatriz Valadares; KREMER, Jeannette Marguerite. Fontes de informação para pesquisadores e profissionais. Belo Horizonte: Ed. da UFMG, 2000. $319 p$.

CAPES. Portal de Periódicos. Disponível em: <https://www.periodicos.capes. gov.br/>. Acesso em: 09 ago. 2017.

CHIAVENATO, Idalberto. Administração de recursos humanos: fundamentos básicos. 5. ed. São Paulo, SP: Atlas, 2003. 205 p.

CHIAVENATO, Idalberto. Iniciação à teoria das organizações. Barueri, SP: Manole, 2010. 268p. COELHO NETTO, José Teixeira. Semiótica, informação e comunicação. São Paulo: Perspectiva, 1983. 223p.

CUNHA, Maria Luísa Monteiro da. Tema 5: bibliotecas universitárias. In: CONGRESSO BRASILEIRO DE BIBLIOTECONOMIA E DOCUMENTAÇÃO, 7, 1973, Belém. Anais ... Rio de Janeiro: IBBD, 1977. p. 229-250.

CUNHA, Murilo Bastos da. Desafios na construção de uma biblioteca digital. Brasília, Ciência da Informação, Brasília, v. 28, n. 3, p. 257-268, set./dez.1999.

CUNHA, Murilo Bastos da; DIÓGENES, Fabiene Castelo Branco A trajetória da biblioteca universitária no Brasil no período de 1901 a 2010. Encontros Bibli: revista eletrônica de biblioteconomia e ciência da informação, v. 21, n. 47, p. 100-123, set./dez., 2016. ISSN 15182924. DOI: 10.5007/1518-2924.2016v21n47p100. Disponível em: https://periodicos.ufsc.br/index.php /eb/article/view/1518-2924.2016v21n47p100>. Acesso em: 30 jan. 2018.

FERREIRA, Bruno Cesar de Freitas; CASTRO FILHO, Cláudio Marcondes de. A relação entre a bibliografia e a formação do profissional da informação. Rebecin, v. 1, n.2, p. 19-36, jun./dez. 2015. ISSN:2358-3193. Disponível em: <http://abecin.org.br/portalderevistas/index.php/rebecin/article/view/14 >. Acesso em: 09 abr. 2017.

FERREIRA, Lusimar Silva. Bibliotecas universitárias brasileiras: análise de estruturas centralizadas e descentralizadas. São Paulo: Pioneira; [Brasília]: INL, 1980. 118 p.

INEP. Avaliação dos cursos de graduação. Brasília, DF, 2015. Disponível em: <http://portal.inep. gov.br/web/guest/avaliacao-dos-cursos-de-graduacao>. Acesso em:01 fev. 2018.

INEP. Avaliação in loco: referenciais no âmbito do SINAES. Brasília, DF, 2015. v. 5, 290 p. Disponivel em: <http://portal.inep.gov.br/documents/186968/484109/SINAES++Sistema+Nacional+de+Avalia\%C3\%A7\%C3\%A30+da+Educa\%C3\%A7\%C3\%A3o+Superior+Vol+ 5/ee07ce50-a60f-4614-9aac-01bfe168df5f?version=1.2>. Acesso em: 30 jan. 2018.

INEP. Avaliação in loco e novos instrumentos de avaliação de instituições de educação superior e cursos de graduação: subsídios para atuação de procuradores institucionais (PI). Brasília, DF, $2018 . \quad$ Disponível em: <http://download.inep.gov.br/educacao_superior/avaliacao_institucional/avaliacao_inloco/Capacitacao_Procuradores_Educacionais_Institucionais_2018.pdf>. Acesso em: 15 set. 2018.

INEP. Instrumento de avaliação de cursos de graduação presencial e a distância. Brasília, DF: INEP, 2015. Disponível em: <http://download.inep.gov.br/educacao_ superior/avaliacao_cursos_graduacao/instrumentos/2015/instrumento_cursos_graduacao_pu blicacao_agosto_2015.pdf>. Acesso em: 11 abr. 2017. 
INEP. Instrumento de avaliação de cursos de graduação presencial e a distância. Brasília, DF: INEP, 2016. Disponível em: <http://download.inep.gov.br/educacao _superior/avaliacao_cursos_graduacao/instrumentos/2016/instrumento_2016.pdf >. Acesso em: 11 abr. 2017.

INEP. Instrumento de avaliação de cursos de graduação presencial e a distância: autorização. Brasília, DF: INEP, 2017a. Disponível em: <http://download.inep.gov.br/ educacao_superior/avaliacao_cursos_graduacao/instrumentos/2017/curso_autorizacao.pdf.>. Acesso em: 11 jan. 2018.

INEP. Instrumento de avaliação de cursos de graduação presencial e a distância: reconhecimento, renovação de reconhecimento. Brasília, DF: INEP, 2017b. Disponível em: $<$ http://download.inep.gov.br/educacao_superior/avaliacao_cursos

_graduacao/instrumentos/2017/curso_reconhecimento.pdf>. Acesso em: 11 jan. 2018.

INEP. Nota técnica no 16/2017/CGACGIES/DAES, 2017. Disponível em: $<$ http://download.inep.gov.br/educacao_superior/avaliacao_cursos_graduacao/legislacao_nor mas/2017/nota_tecnica_sei_inep_0126132.pdf>. Acesso em: 01 fev. 2018.

KEELING, Ralph. Gestão de projetos: uma abordagem global. São Paulo: Saraiva, 2002. 293p.

LEMOS, Antonio Agenor Briquet de. Bibliotecas. In: CAMPELO, Bernadete Santos; CALDEIRA, Paulo da Terra. Introdução às fontes de informação. 2.ed. Belo Horizonte: Autêntica, 2008.

LUBISCO, Nídia M. L. (Org.). Biblioteca universitária: elementos para o planejamento, avaliação e gestão. Salvador: EDUFBA, 2011. 263 p.

LUBISCO, Nídia M. L. A biblioteca universitária brasileira: um modelo para avaliar seu desempenho. PontodeAcesso Revista do Instituto de Ciência da Informação, Salvador, v. 2, n. 1 1, p. 153-199, jun. 2008.2017 <https://portalseer.ufba.br/index.php/revistaici/article/view/2671>. Acesso em: 03 jul. 2017. DOI: http://dx.doi.org/10.9771/1981-6766rpa.v2i1.2671.

LUBISCO, Nídia M. L. A Biblioteca Universitária no Processo de "Avaliação das Condições de Oferta" dos Cursos de Graduação pelo MEC: o caso da UFBA. 2001. Dissertação (Mestrado em Ciência da Informação) - Instituto de Ciência da Informação, Universidade Federal da Bahia. Salvador. Orientador: Dora Leal Rosa.

LUBISCO, Nídia M. L. Avaliação de biblioteca universitária: projeto para sua construção em plataforma web. Salvador, 2017. $8 \mathrm{f}$. Projeto aprovado pela plenária do Departamento de Fundamento e Processos Informacionais, do Instituto de Ciência da Informação, UFBA, em 27 de julho de 2017. Não publicado.

LUBISCO, Nídia M. L. Bibliotecas universitárias, seus serviços e produtos: transposição de um modelo teórico de avaliação para um instrumento operacional: relatório de pesquisa desenvolvida durante estágio pós-doutoral, na Universidad de Salamanca (ES). PontodeAcesso Revista do Instituto de Ciência da Informação, Salvador, v. 8, n. 3, p. 56-61/ 80-141, dez. 2014. Disponível em: <https://portalseer.ufba.br/index.php/revistaici/article/view/12834>. DOI: http://dx.doi.org/10.9771/1981-6766rpa.v8i3.12834

LUBISCO, Nídia M. L. La evaluación en la biblioteca universitaria brasileña: evolución y propuesta de mejora. 2007. 405 p. Tese (Doctorado en Documentación) - Universidad Carlos III de Madrid.

LUBISCO, Nídia M. L. Tipologia de biblioteca segundo as variáveis função, acervo e público. Salvador, 2016. Disponível em: <https://repositorio.ufba.br/ri/handle/ri /23819>. 
MANO GONZÁLEZ, M. de la. Propuesta de un sistema de evaluación para bibliotecas universitarias. Revista española de Documentación Científica, [S.I.], v. 21, n. 2, p. 174-197, june 1998. ISSN 1988-4621. Disponível em: <http://redc.revistas.csic.es/index.php/redc/article/view/353>. Acesso em: 06 fev. 2018. DOI: http://dx.doi.org/10.3989/redc.1998.v21.i2.353.

MASETTO, Marcos Tarciso. Competência pedagógica do professor universitário. 3.ed. São Paulo: Summus, 2015. 207p.

MIRANDA, Antonio. Biblioteca universitária no Brasil: reflexões sobre a problemática. Brasília, DF: Capes, $\quad 1978 . \quad$ Disponível em: <http://antoniomiranda.com.br/ciencia_informacao/BIBLIOTECA_UNIVERSITARIA_.pdf >. Acesso em: 08 set. 2017.

PACHECO, Eliezer. Os institutos federais uma revolução na educação profissional e tecnológica. Brasília, DF: [2009?]. MEC, Disponível em: <http://portal.mec.gov.br/setec/arquivos/pdf/insti_evolucao.pdf>. Acesso em: 08 set. 2017.

THOMPSON, James; CARR, Reg. La biblioteca universitaria: introducción a su gestión. Trad. de David Torra Ferrer. Madrid: Fundación Sánchez Ruipérez; Pirámide, 1989.

UNIVERSIDADE FEDERAL DA BAHIA. Pró- Reitoria de Planejamento e Orçamento. UFBA em números Retrospectiva Especial $\mathbf{7 0}$ anos. Salvador: UFBA, 2016. Disponível em:<https://proplan.ufba.br/sites/proplan.ufba.br/files/UFBA \%20em\%20n\%C3\%BAmeros\%20 Retrospectiva\%20Especial\%2070\%20Anos\%2007fev.pdf>. Acesso em: 08 set. 2017.

ZANITO, Maria Amélia Sabbag; PINTO, Maira Lúcia Accioly Teixeira. Gestão da instituição de ensino e ação docente. Curitiba: Ibepex, 2008. 134 p. 